\title{
Gastrointestinal diagnosis using non-white light imaging capsule endoscopy
}

\section{Citation for published version:}

Cummins, G, Cox, BF, Ciuti, G, Anbarasan, T, Desmulliez, MPY, Cochran, S, Steele, R, Plevris, JN \& Koulaouzidis, A 2019, 'Gastrointestinal diagnosis using non-white light imaging capsule endoscopy', Nature Reviews Gastroenterology and Hepatology, vol. 16, pp. 429-447. https://doi.org/10.1038/s41575-019-0140Z

\section{Digital Object Identifier (DOI):}

10.1038/s41575-019-0140-z

\section{Link:}

Link to publication record in Heriot-Watt Research Portal

\section{Document Version:}

Peer reviewed version

\section{Published In:}

Nature Reviews Gastroenterology and Hepatology

\section{Publisher Rights Statement:}

This is a post-peer-review, pre-copyedit version of an article published in Nature Reviews Gastroenterology and Hepatology. The final authenticated version is available online at: https://doi.org/10.1038/s41575-019-0140-z

\section{General rights}

Copyright for the publications made accessible via Heriot-Watt Research Portal is retained by the author(s) and / or other copyright owners and it is a condition of accessing these publications that users recognise and abide by the legal requirements associated with these rights.

\section{Take down policy}

Heriot-Watt University has made every reasonable effort to ensure that the content in Heriot-Watt Research Portal complies with UK legislation. If you believe that the public display of this file breaches copyright please contact open.access@hw.ac.uk providing details, and we will remove access to the work immediately and investigate your claim. 


\section{Gastrointestinal diagnosis using non-white light imaging capsule endoscopy}

Gerard Cummins ${ }^{1}$, Benjamin F Cox², Gastone Ciuti ${ }^{3}$, Thineskrishna Anbarasan ${ }^{2}$, Marc P.Y. Desmulliez ${ }^{1}$, Sandy Cochran ${ }^{4}$, Robert Steele ${ }^{2}$, John N Plevris ${ }^{5}$, Anastasios Koulaouzidis ${ }^{6}$

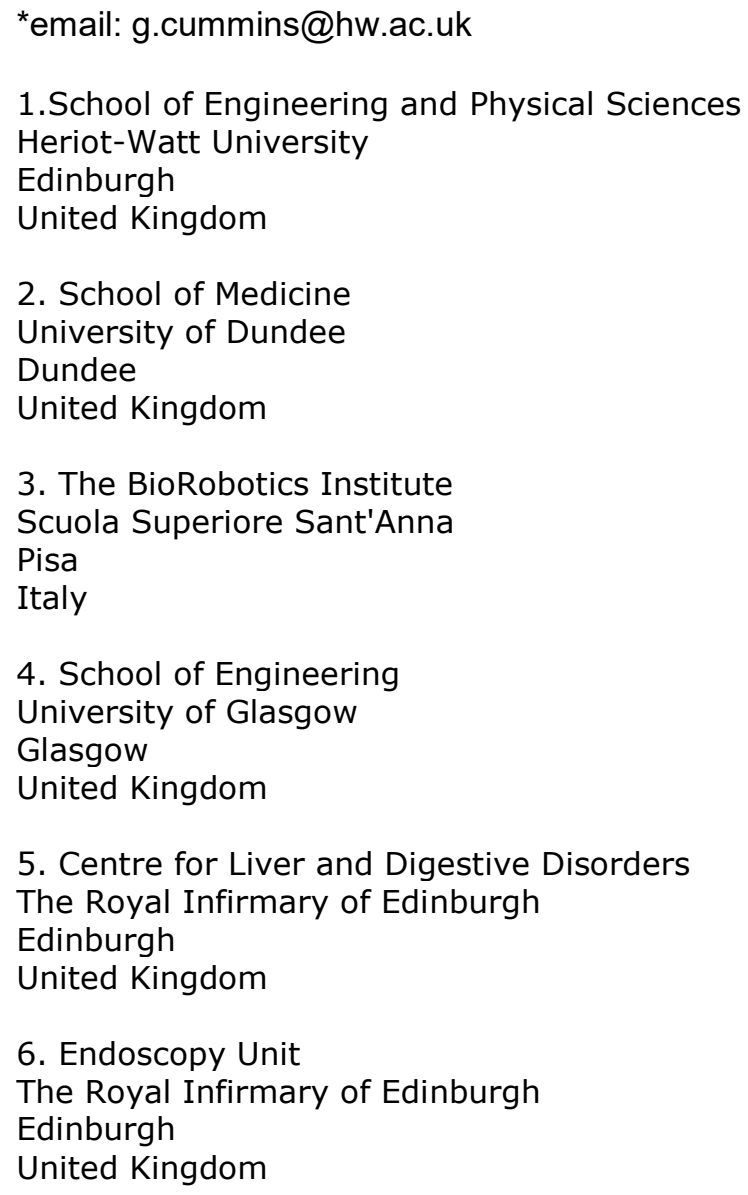


1 Key points:

- White light imaging (WLI) remains the dominant diagnostic modality in capsule endoscopy after nearly two decades of clinical use.

- WLI technology limits diagnosis to the mucosal surface of the gut due to the limited penetration depth of optical wavelengths beyond the tissue surface

- In the past fewyears there has been an increase in the application of non-WLI diagnostic imaging and sensing technologies to capsule endoscopy, some of which are at a more advanced stage of testing than others.

- Integrating specific diagnostic imaging technologies into capsule endoscopy devices enables submucosal imaging, improved differentiation between malignant and benign tissue and new avenues for investigating the aetiology of disease.

- Many of these capsules require further testing to determine their clinical efficacy fully due to the small sample sizes of the reported studies.

- $\quad$ New diagnostic capsule designs will provide new opportunities for improved computer-aided diagnosis, virtual biopsy and capsule localization that could benefit clinical practice in the future. 


\section{Abstract}

2 Capsule endoscopy (CE) has proved to be a powerful tool in the diagnosis and management of small bowel 3 disorders since its introduction in 2001. However, white light imaging (WLI) is the principal technology used in clinical 4 CE at present, and therefore, CE is limited to mucosal inspection, with diagnosis remaining reliant on visible 5 manifestations of disease. The introduction of WLI CE has motivated a wide range of research to improve its 6 diagnostic capabilities through integration with other sensing modalities. These developments have the potential to 7 overcome the limitations of WLI through enhanced detection of subtle mucosal microlesions and submucosal and/or 8 transmural pathology, providing novel diagnostic avenues. Other research aims to utilize a range of sensors to 9 measure physiological parameters or to discover new biomarkers to improve the sensitivity, specificity and thus the 10 clinical utility of CE. This multidisciplinary Review summarizes research into non- WLI CE devices by organizing them 11 into a taxonomic structure on the basis of their sensing modality. The potential of these capsules to realize clinically 12 useful virtual biopsy and computer- aided diagnosis (CADx) is also reported. 


\section{I. [H1]INTRODUCTION}

Capsule endoscopy (CE) offers a minimally invasive method to visualize the gastrointestinal $(\mathrm{Gl})$ tract. The first $\mathrm{CE}$ system approved for clinical use was the M2A capsule (Given Imaging, Yoqneam, Israel) in 20011. Since then, several companies have introduced CE systems ${ }^{2}$. As shown in Table 1, commercially available CE systems primarily rely on white light imaging (WLI), which images the mucosal surface with light within the visible spectrum to enable evaluation of the gastrointestinal lumen and mucosa. CE has been investigated as a diagnostic tool for gastrointestinal diseases, such as bleeding, IBD, colorectal cancer (CRC) and Barrett's oesophagus, with varying degrees of success.

Further developments in CE technology have explored the feasibility of other imaging modalities such as microultrasonography $(\mu \cup S)^{3,4}$ and infrared light ${ }^{5}$. Despite the potential offered by these alternative imaging modalities, WLI CE remains most widely used and studied in clinical practice ${ }^{6,7}$. This Review discusses the limitations of conventional WLI CE in the diagnosis of gastrointestinal disease and gives an overview of the non-WLI capsules currently available on the market or progressing towards clinical translation.

\section{II. [H1]CLINICAL USE OF CAPSULE ENDOSCOPY}

The ability to investigate small bowel pathology, particularly in segments inaccessible by conventional endoscopy, has been the cardinal motive for the development of WLI CE systems. Additional advantages of CE over conventional endoscopy include removing the need for patient sedation, increased patient acceptance and reduced costs $^{8-10}$. Recommendations for the use of CE systems in the colon remain primarily confined to surveillance for patients with an incomplete assessment or contraindications to conventional endoscopy, which is more sensitive and offer interventional options ${ }^{1}$. Guidelines for the use of CE in clinical practice provided by the European Society of Gastroenterology (ESGE) and the American Gastroenterological Association (AGA) are summarized in Table 2. An overview of the evidence basis for the use of CE in the diagnosis of various pathologies is provided in Supplementary Table 1.

\section{[H2]Small Bowel}

In a meta-analysis comprising 396 patients with small bowel bleeding, the use of CE was associated with superior diagnostic yield compared with both enteroscopy and small bowel radiography ${ }^{11}$. CE is therefore recommended as 
1 the first-line investigation modality for obscure gastrointestinal bleeding (OGIB), which is defined as gastrointestinal tract bleeding of untraceable origin on esophagogastroduodenoscopy (EGD) and colonoscopy ${ }^{1}$. A limitation of current WLI CE systems is the lack of interventional capability to manage small bowel lesions. By contrast, doubleballoon enteroscopy (DBE), which relies on the use of a "push and pull" technique assisted by the alternate inflation and deflation of two distally located overtube balloons that enables the endoscope to be advanced either in antegrade (oral introduction) or retrograde (anal introduction) manner, offers the opportunity to perform therapeutic interventions such as injection of hypertonic saline adrenaline and argon plasma coagulation ${ }^{6}$. The use of DBE alone has a poorer diagnostic yield (diagnostic yield 56\%) than CE ( diagnostic yield 62\%), but a complementary strategy of DBE following positive CE has improved detection of OGIB ( diagnostic yield $75 \%)^{12}$ and improved outcomes in managing OGIB (reduced recurrent bleeding and requirement for blood transfusion) ${ }^{13}$. Taken together, these findings suggest that performing DBE is a rational approach in patients with positive CE findings requiring biopsy or therapeutic intervention ${ }^{14}$.

Duodenal biopsy (showing villous atrophy) with EGD complemented by raised serological markers is essential for a definitive diagnosis of coeliac disease ${ }^{15}$. In patients contraindicated for EGD or declining the procedure but with positive coeliac serology and unremarkable findings on EGD, small bowel CE can be a useful diagnostic tool ${ }^{16}$. Small bowel CE enables assessment of complications associated with coeliac disease (such as intestinal T-cell lymphoma and ulcerative jejunitis) and image magnification to identify patchy or distal areas of villous atrophy, which can be missed on standard upper digestive endoscopy ${ }^{17,18}$.

Small bowel CE has consistently shown high sensitivity and specificity for the diagnosis of Crohn's disease. In a meta-analysis including 428 patients, CE had a superior diagnostic yield than ileoscopy, small bowl radiography, CT enterography and magnetic resonance enterography (MRE) in patients with suspected Crohn's disease ${ }^{19}$. More recent studies quantified the diagnostic yield of CE in patients with suspected Crohn's disease to be $76.6 \%$ compared with $44.7 \%$ of $\mathrm{MRE}^{20,21}$. In addition, although MRE enables the investigation of transmural pathology, it is limited by increased examination time, poorer spatial resolution and increased costs compared with $C E^{22}$. CE can have an important role in monitoring Crohn's disease activity and response to therapy, particularly with the availability of established disease activity scoring systems (for example the Capsule Endoscopy Crohn's Disease Activity Index, also known as the Niv score and the Lewis score $)^{23}$. 
Inadequate ampulla of Vater (AoV) visualization, acting as a surrogate marker of segmental visualization of the duodenum, was identified as a limitation of axial $C^{24}$. Improved detection of the ampulla of Vater was reported in a separate study that evaluated the use of a lateral-viewing CE platform, the CapsoCam Plus (CapsoVision, California, USA) (diagnostic yield 70\%) compared to axial-viewing CE (diagnostic yield $10-44 \%$ ), 25 . In a prospective study of 20 patients with familial adenomatous polyposis and Peutz-Jeghers syndrome, CE was superior to MRE in identifying polyps of $<5 \mathrm{~mm}$ diameter ${ }^{26}$. CE is safe in patients who have undergone intestinal surgery and is recommended by the British Society of Gastroenterology every 1-3 years for the long-term surveillance of hereditary polyposis syndromes due to the increased risk of $\mathrm{CRC}^{27,28}$.

\section{[H2]Colon}

The wide lumen of the colon means that small bowel CE devices are more likely to move in a random manner, impairing high-quality image acquisition. Newer capsule endoscopes have been developed with double headed lenses, longer battery time and variable image capture rate with improved detection of colonic pathology ${ }^{29,30}$. In a meta-analysis of studies involving 1292 patients that compared the performance of second-generation colon CE device (COLON2; Medtronic, Minneapolis, USA) with colonoscopy, it was found that COLON2 had a sensitivity and specificity of $86 \%$ and $88.1 \%$ respectively for detecting polyps $>6 \mathrm{~mm}$, and detected all invasive cancers $(n=11)$ identified on colonoscopy ${ }^{31}$. COLON 2 had an equivalent performance to colonoscopy for larger polyps (>10mm) ${ }^{31}$, a confounding factor is adequacy of bowel preparation ${ }^{31}$. Specific regimes for optimum bowel cleansing are being developed but they are more vigorous than those used in conventional colonoscopy, thus potentially limiting acceptability by patients. For all the above reasons, colonic CE can be considered if colonoscopy is not complete, the procedure is contraindicated or if patients are unwilling to undergo the procedure ${ }^{1}$.

\section{[H2]Oesophagus}

The PillCam ESO (Medtronic, Minneapolis, USA), developed in 2004, is the only WLI CE system licensed for examining the oesophagus. The capsule is equipped with a camera at both ends to improve detection of ooesophageal pathology, in contrast to the single camera CE systems used for the small bowel. Oesophageal CE is increasingly considered as a potentially useful alternative investigative modality to EGD, given that EGD is more uncomfortable for the patient and more labour intensive to perform 32,33 . However, currently EGD remains the superior diagnostic tool for the detection of oesophageal pathology (e.g. Barrett oesophagus, ooesophageal varices) ${ }^{34}$. 
2

As shown in Table 1, the differences between available WLI capsules lie mainly with the number of imaging devices, the frame rate and battery life. Typically, these battery-powered WLI capsules consist of one or more imagers (typically with a resolution of $320 \times 240$ pixels ${ }^{35}$ ), $4-6$ light emitting diodes (LEDs) to provide illumination, an onboard microprocessor, and a telemetry system for transmitting images to an external receiver attached to a data logger that is worn by the patient. Although the imaging resolution of $C E$ is less than the high-definition resolution possible with conventional endoscopy owing to the constraints of miniaturization, numerous studies have demonstrated good diagnostic yield of various CE devices within the small bowel for the detection of OGIB, iron deficiency anemia and coeliac disease ${ }^{36,37}$. However, the small number of comparative studies conducted so far have shown no meaningful advantage of one type of WLI CE over another ${ }^{38-43}$.

The reliance of CE solely on WLI technology currently restricts it to the detection of mucosal manifestations of disease and prevents the evaluation of submucosal and transmural pathology ${ }^{44}$. Furthermore, reliance on WLI alone opens up interpretation challenges regarding visually obscured or occult lesions, variability in appearance, nonhomogeneous distribution and occurrence in microfoci45,46. Additionally, the specificity of diagnosis based on visual changes is not reliable owing to similarities in the mucosal appearance of different small bowel diseases such as coeliac disease, microscopic colitis and IBD ${ }^{47}$. Finally, sensitivity declines when encountering low grade diseases that have not fully manifested themselves to the human eye ${ }^{48}$.

(1)

In the past few years, research on $\mathrm{CE}$ as a platform to improve diagnosis of gastrointestinal disease and to understand the underlying pathophysiology has expanded. Two research trends have been observed with regards to diagnosis. The first is the use of alternative imaging technologies, such as ultrasonography, fluorescence imaging and optical coherence tomography (OCT) and the second is the integration of non-image-based sensors for the measurement of physiological parameters such as $\mathrm{pH}$, pressure or temperature. As seen in Table 3 , capsules with these capabilities are still in early development with technical challenges to be overcome and further clinical testing required. 
[H2]Alternative Imaging

Visualizing the gastrointestinal tract using imaging alternative to WLI has the potential to enable observation of previously unseen features, and to improve diagnostic sensitivity, specificity and accuracy. Attempts to overcome the recognized limitations of $\mathrm{WLI}$ in conventional endoscopy have spurred development of alternative imaging technologies such as narrow-band imaging (NBI) and chromoendoscopy ${ }^{49,50}$. Both methods increase tissue contrast to improve visualization but by different means. NBI incorporates optical filters so that only blue (415 nm wavelength) and green (540 $\mathrm{nm}$ wavelength) light is emitted, thereby enhancing the appearance of superficial mucosal capillaries and mucosal surface patterns and increasing hemoglobin absorption to make blood vessels appear darker. In chromoendoscopy, various dye solutions are sprayed on to the gastrointestinal mucosa to improve the detection of subtle mucosal dysplastic changes associated with chronic IBDs, such as ulcerative colitis. Disadvantages of the use of exogenous markers include potentially unequal distribution, pooling which can obscure lesions, and lengthening of the duration of the procedure ${ }^{51}$. These imaging modalities have also been integrated into $\mathrm{CE}^{52-55}$ but studies have cast doubt on their efficacy compared with standard WLI capsules ${ }^{56-59}$. Other alternative imaging technologies such as $\mu \mathrm{US}$, fluorescent imaging and OCT address some of the limitations associated with WLI technology. Examples of some of these imaging modalities are shown in Fig. 1.

\section{[H3] Ultrasonographic imaging}

Following the acceptability of endoscopic ultrasonography (EUS) in routine clinical use, the inclusion of ultrasonography into a capsule was a desirable step to improve CE diagnostic capabilities beyond optical imaging. The development of ultrasonographic capsule endoscopy (USCE) is currently in its infancy and was being developed by a number of teams, including the Khuri-Yakub60 group at Stanford University, USA; the Qiu ${ }^{61}$ group at the Shenzhen Institutes of Advanced Technology, China; and the Sonopill Program led by Cochran ${ }^{3,4,62}$, UK. Previous attempts have included the Endoscope Capsule using Ultrasound Technology (TROY) ${ }^{63}$ project, which was unable to miniaturize the system to fit within the dimensions of a swallowable capsule before the end of the project and work by Lee et al. ${ }^{64}$, which was not able to identify a suitable means for achieving long-term rotation of the ultrasound transducer, although they produced a capsule with the required dimensions that was successfully tested in vivo. The common aim of these projects was to develop a capsule capable of transmural gastrointestinal imaging to detect submucosal (intramural) pathology. 
At the heart of USCE is the development and integration of a suitable ultrasound transducer. Both Khuri-Yakub et al. and Cochran et al. have explored the possibility of fabricating miniaturized multi-element ring arrays capable of providing a $360^{\circ}$ image of the bowel wall65,66. Cochran has also focused on single-element transducers, as have Qiu and Lee ${ }^{4,61,64}$. Concurrently, Qiu et al. have investigated a mechanical approach using a single-element transducer actuated by an oscillating motor that enables radial imaging of the gut wall ${ }^{61}$. Transducer frequency makes an important contribution to USCE function through its strong effect on image resolution (two-point discrimination) and depth of penetration. Conventional EUS typically employs ultrasound frequencies in the range $5-18 \mathrm{MHz}$, corresponding to axial resolutions of $\sim 0.2-0.8 \mathrm{~mm}$ and depths of $\sim 2-8 \mathrm{~cm}$, respectively ${ }^{67}$. Lower frequencies $(5-20$ $\mathrm{MHz}$ ) can enable imaging of organs located beyond the wall of the gastrointestinal tract, whereas higher frequencies $(\geq 25 \mathrm{MHz})$ can provide more detailed images of the gut wall. Higher frequencies are employed when staging local tumour burden using a tumuor-node-metastatis (TNM) classification system, as they enable reliable means of determining tumour size and invasive extent (T stage) as well as proximal lymph node spread ( $\mathrm{N} \mathrm{stage})^{68-70}$.

$\mu \mathrm{US}$ miniprobes introduced via the biopsy channel of conventional endoscopes for CRC staging have improved axial and lateral image resolution with higher than conventional EUS frequencies $68,71,72$. These higher frequencies result in highly detailed subsurface information that includes structural and cellular tissue composition. Additionally, there is a simultaneous decrease in the depth of tissue penetration as the frequency is increased, which has the potential to mitigate confounding information (for example, adjacent bowel loops versus edema) caused by deep penetrating soundwaves at standard frequencies in the $5-20 \mathrm{MHz}$ range ${ }^{73}$. The Qiu and Cochran groups investigated the potential benefit of high frequency ( $>25 \mathrm{MHz}$ ) ultrasonography for high resolution, known as $\mu \mathrm{US}$, in their respective capsules. Cochran has demonstrated the potential of a capsule with multiple single-element ultrasonic transducers operating at $30 \mathrm{MHz}$ in imaging the layers constituting the small bowel ${ }^{4}$. Although USCE is in its early stages, the principle of submucosal bowel wall imaging is attractive as USCE will enable deeper tissue analysis with the potential of detecting transmural inflammation and thus has the capability to assess disease activity in Crohn's disease.

\section{[H3]Autofluorescence imaging}

Autofluorescence imaging (AFI) uses short wavelengths of light, typically 380-500 nm, to illuminate tissue, exciting either endogenous or exogenous fluorophores to differentiate healthy and malignant tissue. The incident light absorbed by the tissue causes the fluorophores to emit light at longer wavelengths, typically $490-590 \mathrm{~nm}$. One study has shown that autofluorescence is reduced by a factor of 3 to 12 in malignant tissue compared with healthy tissue ${ }^{74}$. 
Various studies have compared the efficacy of conventional AFI endoscopy to that of conventional WLI endoscopy for the detection of gastrointestinal disease. Several of these studies have shown that AFI increases the detection rate of diseases such as colorectal adenoma ${ }^{75}$ and polyps ${ }^{76}$ compared with WLI75-77. The efficacy of AFI in diagnosing IBDs such as ulcerative colitis has also been examined. Studies have shown a correlation between the intensity of $\mathrm{AFI}$ images and the severity of the inflammation ${ }^{78,79}$, with intensity shown to be a useful marker of active inflammation in ulcerative colitis ${ }^{80}$. Because of this potential, there is considerable research interest in the use of AFI with conventional endoscopy, so it was logical that the integration of AFI with CE would be explored to improve the diagnostic capabilities of CE. The integration of AFI CE has led to the development of several prototype imaging devices such as those being created by the Cummings group ${ }^{81}$, and has also contributed use of fluorescence as a sensing modality as evidenced by the work of Demosthenous et al. ${ }^{82}$ and Nemiroski et al. ${ }^{83}$

Single photon avalanche diode (SPAD) imaging arrays, capable of detecting a single photon of light, have been successfully used in AFI CE to improve the detection of endogenous fluorophores at low light intensity, removing the risk of phototoxic reactions and photobleaching of the fluorophores ${ }^{84}$. Furthermore, the use of complementary metaloxide-semiconductor (CMOS) technology in the fabrication of both the SPAD imager and the associated electronic systems is vital to reduce the power required, allowing the capsule to be powered by silver-oxide batteries for up to 15 hours, a lifetime similar to those of some clinical CE devices.

SPAD imagers have been used in wireless CE prototypes developed by Al-Rawhani et al. ${ }^{81}$. The highly sensitive SPAD pixels generate a pulse in response to each impinging photon, which enables individual photons due to autofluorescence to be counted. The latest version of the capsule contains a $32 \times 32$ pixel SPAD imager sufficient to demonstrate the diagnostic potential of this technology ${ }^{81}$. However, an increase in resolution is required for routine clinical practice. Illumination in the prototype developed by Al-Rawhani et al. is provided by an inexpensive, compact LED at $468 \mathrm{~nm}$ with an emitted power of $78 \mu \mathrm{W}$ being sufficient for this imager. Sensitivity is further improved by filtering out light other than that owing to fluorescence emission.

A common drawback of AFI techniques is that the signal from cancerous cells can be obscured by the autofluorescence of healthy cells. The capsule developed by Al-Rawhani et al. has yet to undergo in vivo trials, but benchmark tests have been conducted to assess its capability to detect autofluorescence from FAD. an endogenous fluorophore associated with tumour growth, and the effect of haemoglobin on autofluorescence with a fluorescence 
emission peak of $520 \mathrm{~nm}$. The minimum amount of FAD detectable with this system is $12.5 \mu \mathrm{M}$, rising to $20 \mu \mathrm{M}$ in a gut-mimicking imaging phantom. Similarly, this capsule can easily detect $20 \mu \mathrm{M}$ of fluorescein isothiocyanate (FITC) The system can also detect a reduction in autofluorescence upon the introduction of haemoglobin ${ }^{81}$.

Capsules capable of sensing autofluorescence or fluorescence, as opposed to imaging capsules such as the AlRawhani capsule, were created for gastrointestinal diagnosis by Demosthenous et al. ${ }^{82}$ and Nemiroski et al. ${ }^{83}$. These devices detect light with photo-diodes rather than SPAD imagers. Demosthenous et al. ${ }^{82}$ used their CE device to measure the changing level of fluorescent light generated by low concentrations of an exogenous infrared fluorescent marker (indocyanine green (ICG)) to screen for cancer in ex vivo porcine small intestine. ICG was chosen as the fluorophore, as it is used to tag cancerous cells with a fluorescent signal in other regions of the gastrointestinal $\operatorname{tract}^{85,86}$ and the absorption spectrum can be modified through changes in concentration. This latter property enables the excitation wavelength to be altered for optimal detection of specific pathologies or improved tissue penetration; for instance, at low concentrations, such as those expected in small cancers, the optimum excitation wavelength is $780 \mathrm{~nm}$. Increasing the concentration causes a second absorption wavelength to appear at $708 \mathrm{~nm}^{82,87}$. Demosthenous and colleagues designed their autonomous system for use with $780 \mathrm{~nm}$ wavelength excitation, as the deeper tissue penetration depth at this wavelength is more suitable for detecting small cancers ${ }^{88,89}$ and the rate of false positives arising from endogenous fluorophores within surrounding tissue that emit light in the ultraviolet and other parts of the visible spectrum is reduced ${ }^{90}$. The functionality of this capsule has yet to be determined in an in vivo environment. However, ex vivo experiments using porcine intestinal tissue have demonstrated the capability to detect nanomolar to micromolar concentrations of ICG, which are comparable to those that would be expected from tagged small cancers ${ }^{82}$.

Nemiroski and colleagues designed their wireless capsule to detect gastrointestinal bleeding (GIB) ${ }^{83}$. Although WLI CE can be used to identify blood in the stomach, it cannot easily differentiate between past and active GIB in the stomach. Such differentiation is achieved in the Nemiroski capsule through the intravenous injection of fluorescein, a fluorescent contrast agent. Fluorescein is chosen as a proxy for active GIB as it is FDA compliant, has a quantum yield of $\sim 90 \%$ and the optical spectrum (absorption peak at $494 \mathrm{~nm}$, emission peak at $512 \mathrm{~nm}$ ) does not overlap with the autofluorescent spectrum of gastric juices (absorption peak at $288 \mathrm{~nm}$; emission peak at $350 \mathrm{~nm}$ ). The distance between the two pairs of emission and absorption peaks enables fluorescein to act as a biomarker for the detection of blood in the stomach. The capsule uses a miniaturized fluorometer consisting of a LED, optics and photodiode for 
detection of the emitted fluorescent signal. The LED peak wavelength is $465 \mathrm{~nm}$, and the use of filters limits the light from sources other than the fluorescein that is detected by the photodiode. Benchtop tests have demonstrated that the system can detect concentrations of fluorescein as low as $20 \mathrm{nM}$. However, the performance of the system varies with the $\mathrm{pH}$ of the stomach as the spectral properties and quantum yield of fluorescein shift with $\mathrm{pH}$, which can be problematic after the patient ingests water. In vivo trials have yet to be carried out with this capsule.

\section{[H3]Optical coherence tomography}

OCT is a volumetric imaging technology capable of micrometre scale resolution that operates by scanning an optical beam across the sample and measuring the time delay and intensity of backscattered or back-reflected light ${ }^{91}$. Improvements in the speed and sensitivity of OCT technology ${ }^{91}$, coupled with an image resolution comparable with that achieved with conventional histological analysis of excised biopsy (10 $\mu \mathrm{m}$ axial and $30 \mu \mathrm{m}$ lateral resolution), make this an attractive technology for real-time, in vivo virtual biopsy applications. OCT was successfully applied to in vivo studies of the duodenum in $2005^{92,93}$. An image was reconstructed from the measured light that demonstrated that the intestinal villi could be observed ${ }^{93}$. Studies in 2007 showed that OCT combined with EGD could be successfully used to detect coeliac disease by analysis of the villous morphology from the OCT images, with a sensitivity of $82 \%$ and specificity of $100 \%$ achieved in a study of 132 paediatric patients ${ }^{94}$. The potential for OCT in the diagnosis of IBD has been demonstrated by several studies, with the first reporting that transmural inflammation detected by OCT could distinguish Crohn's disease from ulcerative colitis with a sensitivity of $90.0 \%$ and specificity of $83.3 \%{ }^{95}$. A subsequent study also found similar discrimination between ulcerative colitis and Crohn's disease ${ }^{96}$. Both of these studies involved 2D images; although a subsequent study generated 3D reconstructions of the colon, rectum and anal verge in patients with ulcerative colitis that visualized the presence of large subsurface voids, ulcerations and the absence of a regular crypt pattern ${ }^{97}$.

Attempts to integrate OCT into CE have so far been limited to two, independently produced, tethered capsule endoscopes for diagnosing oesophageal pathology ${ }^{98,99}$. In both referenced cases, the tether encases an optical fibre used to transmit light from an external light source to internal optics that are mechanically scanned to produce the image. The tethered capsule developed by Gora et al. ${ }^{98}$ was $12.8 \mathrm{~mm}$ in diameter and $24.8 \mathrm{~mm}$ long with sideviewing OCT capable of generating radial images at 20 frames per second with $30 \mu \mathrm{m}$ lateral and $7 \mu \mathrm{m}$ axial resolution in humans. This capsule rotated the embedded OCT device using a drive shaft located within the tether sheath. The tethered capsule could be safely used on non-sedated patients, and it could be easily passed down the oesophagus owing to normal swallowing-induced peristaltic force and pulled back manually. However, though 
manual pullback is convenient and simple compared to motorized control, it does not provide the stability or repeatability required for high-resolution volumetric OCT, such as en-face OCT, otherwise known as C-Scan OCT that produces transverse images beyond the mucosal surface, especially at the low frame rates achievable with the actuation mechanism used.

Volumetric OCT was achieved with the tethered capsule developed by Liang et al. ${ }^{99}$ during in vivo studies on porcine models. The capsule was $12 \mathrm{~mm}$ in diameter with a length of $\sim 35 \mathrm{~mm}$. This capsule utilized an OCT device that circumferentially scanned the light from an external source by a microlens that was rotated by an onboard DC micromotor. Longitudinal scanning could be performed by either the manual force applied to the entire capsule via the tether for large field coverage or by distal pneumatic actuation of an internal carriage within a stationary capsule for small field coverage with high stability. An advantage of using an integrated longitudinal scanning stage is the ability to track non-uniformities along the scan trajectory, which facilitates compensation in post-processing. The use of a semi-rigid tether removed the need for peristaltic propulsion as it made manual positioning easier than with the soft tether used by Gora et al. ${ }^{98}$ However, the authors found that the semi-rigid tether made it difficult to achieve smooth longitudinal scanning owing to difficulty in moving the tether at a constant speed of less than a few millimeters per second. Despite these limitations, the tethered OCT capsule achieved an axial resolution of $8.5 \mu \mathrm{m}$ in tissue and scanning frequencies of $250 \mathrm{~Hz}$ and was able to produce volumetric scans with 1,750 frames over an area of $1.3 \mathrm{~mm}^{2}$ and a depth of $3.5 \mathrm{~mm}$ in 7 seconds.

Currently, OCT has not been utilized in a wireless capsule format owing to several remaining technical challenges. One issue is the need to replace the external light source with a battery powered light source within the capsule. Another is the need for short image acquisition times for real-time en-face imaging so that that scans can be produced within a capsule subject to peristaltic motion.

\section{[H3]lonizing Radiation}

lonizing radiation is a high frequency electromagnetic wave or particle, such as x-rays, of sufficient energy to remove an orbital electron from an atom. X-rays and other ionizing radiation can damage or destroy living tissue, so care must be taken to avoid unnecessary or excessive exposure. Alternatively, ionizing radiation can pass through the tissue of the human body and the interaction between this radiation and the tissue can be recorded to generate images of the internal structure of the body. 
Although the development of capsule endoscopy is seen by many as a means of imaging the gastrointestinal tract without the use of ionizing radiation ${ }^{100}$, the limitation of current, commercially available CE to mucosal imaging has spurred development of a range of capsules capable of sub-mucosal imaging, such as OCT and $\mu U S$. The ionizing radiation imaging C-scan system from Check-Cap is the closest to market and has recently gained approval from the FDA for a pilot study ${ }^{101}$. The C-scan system (Check-Cap, Isfiya, Israel) is an autonomous X-ray-based CE system that includes an external data logger and workstation. The novel aspect of this system is the use of a weak X-ray source to image the colon transmurally; furthermore, because of the nature of this imaging modality, bowel preparation consists solely of ingestion of iodine-based contrast agent taken with normal meals during capsule passage ${ }^{102,103}$.

The C-scan CE device is $11.4 \mathrm{~mm}$ in diameter and $34 \mathrm{~mm}$ in length. The X-ray source is a short-lived radioisotope, ${ }^{191}$ Os, with a half-life of 15.4 days, which was chosen to balance the need for a complete examination with environmental concerns regarding device disposal after use. The emitted $65-75 \mathrm{keV} \mathrm{X}$-rays are divided into three rotating beams, enabling a $360^{\circ}$ view of the colon wall. Image formation depends on two types of energy returned to the capsule. The first step occurs when emitted photons interact with the ingested iodine contrast agent, producing X-ray fluorescence at a low energy of $27 \mathrm{keV}$. The second step occurs with Compton scattering of the photons at 52$60 \mathrm{keV}$. By measuring these two events separately, distances from the capsule to colon can be calculated and wall abnormalities can be detected. The capsule is also equipped with an accelerometer and a magnetometer to enable capsule or pathology localization for follow-up. Acquired data is transmitted wirelessly to external receivers located on the patient, and the system is completed by a workstation that enables a number of $2 \mathrm{D}$ and $3 \mathrm{D}$ image reconstructions ${ }^{103,104}$.

A pilot study consisting of 46 individuals between 45 and 68 years of age of unknown gastrointestinal status and assumed to be healthy assessed the functioning C-scan device ${ }^{102}$. A parallel study performed on volunteers, aged 41-70 with no known gastrointestinal pathology, involved the swallowing of a non-functioning capsule was, used to assess device safety ${ }^{102}$. Preparation for examination involved daily ingestion of up to $50-70 \mathrm{ml}$ iodine solution with food until the capsule had transited. One patient experienced a retained capsule in the caecum that was retrieved via conventional colonoscopy during the scheduled follow-up. No other adverse events were reported. The average radiation dose per patient was calculated to be $0.03 \pm 0.0007 \mathrm{mSv}$; for comparison, a typical effective dose for a posterior to anterior chest $\mathrm{x}$-ray is $0.02 \mathrm{mSv}^{105}$ and the dose for a similar 3D CT colonography image is $\sim 8.8 \mathrm{mSv}$, 
with the specific dose dependent upon the performing institute ${ }^{106}$. The detection of pedunculated and sessile polyps, as confirmed by subsequent standard colonoscopy, was reported. Despite the lack of quantitative human data, in vivo pig trial results indicated the device had sufficient resolution to detect $5 \mathrm{~mm}$ diameter implanted silicone beads $^{102}$. As stated by the authors, further validation and direct comparison of the system with standard colonoscopy is required ${ }^{102}$.

\section{[h2]Biophysical Measurements}

Changes in gastrointestinal activity, such as transit time can indicate a pathological condition. To aid this situation several groups have adapted CE to measure changes in physical parameters of the gastrointestinal tract, such as pressure and myoelectric activity. Ingestible capsules to measure other physical parameters, such as temperature, have also been developed for sports medicine rather than gastroenterology and are described here.

\section{[H3]Temperature}

CorTemp by $\mathrm{HQ}$ (Palmetto, FL, USA) is an FDA-approved, wireless capsule that measures internal body temperature with an accuracy of $\pm 0.1^{\circ} \mathrm{C}$. Applications for monitoring internal body temperature are found in several areas, such as sports physiology, firefighting, research and medicine, occupational safety and military ${ }^{107,108}$. These devices have not been used for the diagnosis of GI disease owing to the non-specific nature of temperature changes as a biomarker. One capsule that has been used in the diagnosis of GI disease is the SmartPill (Medtronic, Yoqneam, Israel), which along with an integrated $\mathrm{pH}$ and pressure sensor also incorporates a temperature sensor, though this is used, in conjunction with the other sensors, to aid the measurement of transit time through the various regions of the $\mathrm{GI}$ tract. The temperature sensor has a range of $20-40^{\circ} \mathrm{C}$ with an accuracy of $\pm 1^{\circ} \mathrm{C}$ and is measured at a frequency of $0.05 \mathrm{~Hz}$. This capsule is discussed in greater detail in the section describing $\mathrm{pH}$-sensing capsules.

\section{[H3]Manometry}

Consumed food is moved along the GI tract via the periodic peristaltic contraction of muscles in the oesophagus, stomach, small and large intestines. During and after consumption, highly irregular contractions mix the food and digestive enzymes in the small intestine while slowly moving them towards the large intestine. These contractions are defined as the motility of the gastrointestinal tract. An estimated $40 \%$ of gastrointestinal conditions worldwide are associated with abnormal gastrointestinal motility (dysmotility), resulting in abdominal discomfort, pain and other intestinal problems for $20 \%$ of the general population ${ }^{109,110}$. For example, small intestine dysmotility may be 
symptomatic of irritable bowel syndrome, gastroparesis and chronic idiopathic constipation ${ }^{111}$. However, why and how dysmotility occurs is not fully understood.

Current methods of diagnosing dysmotility include serosally attached electrodes, barium X-ray imaging, scintigraphic imaging and electrogastrography ${ }^{112}$. Endoscopic manometry is a commonly used procedure; this technique involves transnasal insertion of a modified catheter containing a series of pressure sensors into the small intestine. The pressure sensors record the contractile behavior of the gastrointestinal tract for subsequent clinical assessment ${ }^{113}$. As with many endoscopic procedures, manometry can be uncomfortable for patients and most of the small intestine cannot easily be reached. Other methods use balloons to measure the motion of the bowel wall, electropotential recordings associated with peristaltic activity and abdominal acoustic emissions have been found to be imprecise compared with endoscopic manometry ${ }^{114}$. A minimally invasive, reliable and versatile diagnostic tool is therefore an attractive development target for the detection and accurate characterization of gastrointestinal tract dysmotility. Ingestible motility capsules (IMCs) offer an attractive alternative to other test modalities as they provide real-time insitu information about the environment of the gastrointestinal tract, such as pressure, temperature, $\mathrm{pH}$, transit time and potentially capsule location, without the need for ionizing radiation or discomfort to the patient. The acquisition of the gastrointestinal pressure profile via an IMC could replace conventional antroduodenal and colonic studies that use invasive and less well-tolerated manometric catheters to quantify the contractile pressure patterns. Assessment of the pressure profile captured by a motility capsule has the potential to provide richer motility information beyond that currently recorded ${ }^{115}$.

The SmartPill is the only FDA-approved, wireless CE device with pressure sensing capabilities currently on the market ${ }^{116}$. SmartPill contains a temperature sensor $\left(25-49^{\circ} \mathrm{C}\right)$, a $\mathrm{pH}$ sensor $(\mathrm{pH}$ 0.05-9.0), a single pressure sensor with an operating range $0-46 \mathrm{kPa}$ and a sensitivity of $\pm 0.650 \mathrm{kPa}$ that can record the pressure of its environment, and an internal antenna that can transmit captured data wirelessly in real time at $433 \mathrm{MHz}$. The capsule is enclosed in a non-digestible polyurethane shell, battery powered, and is intended for single use. The SmartPill can be used to measure gastric emptying time and small bowel, colon and whole gut transit times by evaluating combined pressure, $\mathrm{pH}$ and temperature profiles. 
1 Though studies have utilized the SmartPill to diagnose gastroparesis ${ }^{117}$ and chronic idiopathic constipation ${ }^{118}$, the presence of a single pressure sensor does not provide sufficient manometric information as it records only the intraluminal pressure in the gastrointestinal tract and is unable to provide information on peristaltic behaviour ${ }^{116,117,119-121}$ unlike conventional manometry. The recommendation by the American and European Neurogastroenterology and Motility societies for the use of SmartPill for regional and whole gut transit time evaluation in individuals with alterations to $\mathrm{GI}$ motility in single or multiple regions ${ }^{122}$ can be predominantly attributed to the multimodal approach of using the $\mathrm{pH}$, pressure and temperature sensor data together. Recording both contractile and intraluminal pressure requires an array of pressure sensors arranged longitudinally and radially around the capsule that are sensitive to pressure changes $<0.133 \mathrm{kPa}$ and can operate between 0 and $25 \mathrm{kPa}$ are required to capture the weak peristaltic or segmentation contraction of the GI tract ${ }^{119}$.

Additionally, while not reported for SmartPill, other prototype pressure sensing capsules of a similar design are susceptible to interference from respiration and heartbeat that dominates the signal and requires further filtering ${ }^{123,124}$. Despite these limitations, improved patient acceptance of IMCs in comparison to conventional comparable to conventional manometry. manometry ${ }^{116}$ and the non-invasive potential of the IMC to capture multiregional GI dysmotility is advantageous in comparison to other methods. However, further work is required before these devices can provide information

\section{[H3] Electrophysiology}

Gastrointestinal motility involves complex behavior governed by hormonal, myogenic and neurogenic factors that act together to mix and propel material along the gastrointestinal tract. In the small intestine, slow waves generated by the interstitial cells of Cajal (ICC) cause smooth muscle cells lining the intestine to polarize and depolarize, leading to contraction and relaxation respectively. Determining the pathophysiological role of these cells in dysmotility has attracted substantial research interest ${ }^{125}$. Several methods have been used to investigate the electrophysiology of the gastrointestinal tract in clinical settings. One approach is the non-invasive transcutaneous measurement of the myoelectric activity of the small bowel via electrogastroenterography (EEnG). However, transcutaneous EEnG suffers from several problems, such as interference between EEnG and cardiorespiratory signals and low EEnG signal amplitude ${ }^{126}$. The relationship between clinical presentation and EEnG data is weak, which hinders clinical acceptance ${ }^{126}$. One method to improve this involves the integration of EEnG within a wireless, ingestible capsule. 
Woo et al. ${ }^{127}$ reported the design, construction and testing of a wireless CE capable of measuring the slow waves

generated by ICC. This $11 \mathrm{~mm}$ diameter, $21 \mathrm{~mm}$ long capsule contained two surgical steel electrodes that contacted with the surrounding mucosa and detected the changing electrical potentials of the intestinal smooth muscles, before subsequent amplification and filtering. The system could operate for up to 18 hours with two coin-size batteries similar to those used in conventional capsule endoscopes. The capsule was tested ex vivo using two, freshly excised, samples of porcine intestine immersed in a modified Krebs solution. The results demonstrated successful detection of myoelectric activity within these tissue samples, but only at a fixed point owing to frictional forces. The two electrodes limited the radial resolution of any electrophysiological mapping of the small intestine but, owing to the passage of the capsule through the intestine, the longitudinal resolution was limited only by the distance between the electrodes. No further results from this research have been provided have been published since 2010, though the authors have adapted some of this technology as a means of electrical propulsion of a CE through the GI tract ${ }^{128}$.

\section{[H2]Biochemical Measurements}

Gastrointestinal disease can be associated with a change in the biochemical profile of luminal contents; for example, levels of fecal calprotectin are elevated in patients with IBD. CE offers a unique opportunity to perform minimally invasive screening in situ, which could enable monitoring of gastrointestinal disease progression when coupled with improved capsule localization methods. Capsules capable of measuring $\mathrm{pH}$, hemoglobin and changes in microbiome metabolic byproducts have been developed in several studies, with varying degrees of success.

\section{$[H 3] p H$}

The $\mathrm{pH}$ of a healthy gastrointestinal tract varies with location, time since ingestion, age and diet ${ }^{129,130}$. Changes in $\mathrm{pH}$ are often used in the diagnosis of gastrooesophageal reflux disease (GERD) ${ }^{131}$ and the measurement of GI transit time through the use of CEs with suitable sensors. However, other studies have sought to demonstrate the potential of changes in $\mathrm{pH}$ as a marker of other $\mathrm{GI}$ diseases with mixed results ${ }^{132-135}$.

Earlier studies used a battery-powered, wireless ingestible $\mathrm{pH}$ telemetry capsule with an onboard transducer comprising two reference electrodes, the output of which is sent to an external data logger via an integrated radiofrequency transmitter ${ }^{136}$. Although these capsules were reported to experience up to $75 \%$ signal loss caused by poor alignment between the transmitting and receiving aerials they were considered an improvement over other methods previously used in vivo. Some studies have demonstrated that ulcerative colitis can cause a decrease in $\mathrm{pH}$ 
within the right colon ${ }^{132,133}$, whereas results for other IBDs such as Crohn's disease have been contradictory ${ }^{134,135}$. Fallingborg et al. found that three of six patients with ulcerative colitis had a proximal colon pH of 2.3 to $3.4^{132}$. The other three patients had normal luminal $\mathrm{pH}$ profiles of between $6.8-7.4$ at the proximal colon. In two other studies, Nugent et al. measured a reduction in colonic luminal $\mathrm{pH}$ to $<5.5$ in two of six patients with ulcerative colitis when compared with healthy controls ${ }^{133}$ and Press et al. observed a slight increase in the higher right colonic luminal pH in 11 patients with ulcerative colitis compared with healthy control individuals ${ }^{134}$. Owing to the limited sample sizes, further work is needed to verify these studies and demonstrate whether $\mathrm{pH}$ can act as a realistic and specific biomarker for IBD or IBD severity.

Since the development of these initial capsules, three other devices capable of detecting changes in luminal $\mathrm{pH}$ have become available commercially. The wireless BRAVO capsule (Medtronic, Yoqneam, Israel) is a $26 \mathrm{~mm} \times 6.3 \mathrm{~mm}$ device that is designed primarily to detect gastrooesophageal reflux disease (GERD) by sensing and recording oesophageal $\mathrm{pH}$ for up to 96 hours $^{137}$. The wireless Intellicap capsule (Philips, Eindhoven, Netherlands) is an $11 \mathrm{~mm}$ diameter, $27 \mathrm{~mm}$ long capsule for targeted drug delivery that uses its $\mathrm{pH}$ sensor to determine when to empty the contents of its drug reservoir into a specific region in the gastrointestinal tract. Initial tests conducted on 10 human volunteers with the Intellicap showed that using the $\mathrm{pH}$ profile for capsule localization agreed with the position determined with scintigraphy in all volunteers ${ }^{138}$. This capsule has been assessed primarily for therapeutic delivery ${ }^{139-141}$.

SmartPill is approved ${ }^{116}$ to investigate gastrointestinal motility via integrated $\mathrm{pH}$, pressure and temperature sensors that are previously described. The temperature and pressure sensing capabilities of this device have been previously discussed. The battery life of the capsule is specified to be up to 5 days, enabling data transmission throughout the entire gastrointestinal tract until excretion. Such a long battery life is achieved partly by adjusting the sampling rates of the sensors after $24 \mathrm{~h}^{142}$. Protocols for measuring the transit time of the capsule from the rate of change of $\mathrm{pH}$ along the gastrointestinal tract have been defined ${ }^{143}$.

Although gastrointestinal motility studies using CE to date have involved small sample sizes of $<100$ participants and had difficulties in experimental design (particularly with respect to selection of participants ${ }^{144}$ ), it has been suggested that the detection of gastric emptying time with CE devices such as SmartPill in patients with suspected gastroparesis has a sensitivity and specificity similar to that of gastric scintigraphy ${ }^{145}$, which is commonly used to 
measure transit time across the length of the GI tract. A systematic review that compared the diagnostic capability of CE devices to gastric scintigraphy, antroduodenal manometry and endoscopy in the diagnostic accuracy of gastric emptying delay, motility assessment and treatment decisions ${ }^{115}$ found, with a low strength of evidence, that SmartPill alone was comparable to gastric scintigraphy. A comparison of the diagnoses obtained with SmartPill and gastric scintigraphy showed an agreement of $59-86 \%$ for positive test results and $64-81 \%$ for negative test results. Overall agreement was in the range of $35-81 \%$. The SmartPill offers a nonradioactive alternative to transit testing modalities, that can provide comparable measurements of gastric emptying time, small bowel transit time, colon transit time and whole gut transit time in a single device, reducing the need for separate regional tests ${ }^{116}$.

Although $\mathrm{CE}$ has primarily used $\mathrm{pH}$ to assess motility, there have been some studies investigating changes in $\mathrm{pH}$ as a means to detect disease using CE. In one study of 16 patients with IBS defined by Rome III criteria and 16 agematched control individuals, no differences in the transit times, gastrointestinal motility and ileal $\mathrm{pH}$ were found between the two groups using the SmartPill146. However, cecal $\mathrm{pH}$ was lower in patients than in the control individuals $(5.12 \pm 0.05$ vs. $6.16 \pm 0.15, \mathrm{P}<0.0001)$, which in turn, meant that the change in the ileo-cecal $\mathrm{pH}$ was also greater in patients than in controls $(-33.8 \% \pm 0.84$ vs. $-18.7 \% \pm 1.5, P<0.0001)$. A moderate correlation between cecal $\mathrm{pH}$ and right colonic contractibility was also observed $(r=0.54, \mathrm{P}=0.002)$. The authors observed a correlation between measured values of cecal $\mathrm{pH}$ and contractile behavior and theorized that the more acidic environment detected in patients with IBS is attributable to excessive fermentation in the cecum, and associated production of short chain fatty acids. This excessive fermentation is thought to be the cause of the reduced proximal colonic motor activity that was detected. They also suggested that cecal $\mathrm{pH}$ measured via $\mathrm{CE}$ provides a useful measure of colonic fermentation, which might aid in the classification of patients with a broad spectrum of functional gastrointestinal disorders such as bloating and distension.

\section{[H3]Soluble Biomarkers}

Various soluble biomarkers can be found within the intestinal lumen, such as proteins, enzymes, microbes and their metabolic products ${ }^{147}$. Some attempts have been made to integrate sensors for the detection of these substances in CE devices. Up to now, these sensors have utilized either electrochemical ${ }^{148,149}$ or optical ${ }^{150-152}$ methods.

The single electrochemical sensing capsule ${ }^{148,149}$ incorporates a multi-electrode sensor with onboard potentiostatic circuits to enable cyclic and pulsed voltammetry of the gastrointestinal fluid surrounding the capsule. To date, these capsules have been tested only in vitro using fecal water to demonstrate repeatable and reliable measurement. 
1 However, the shapes of voltammograms produced by the metal electrodes of the electrochemical sensors were shown to change with time ${ }^{148}$. This result was partially attributed to the adsorption of organic matter onto the electrode surface, which would result in a reduced effective area for the electrochemical reactions used to sense the surrounding gastrointestinal fluid. Mass transfer of the analyte to the sensor surface determines the response of electrochemical sensors. Hence, a change in surface area of the working electrode could potentially lead to erroneous measurement of the concentration of the constituent soluble biomarkers of interest, raising questions about the long-term stability of these devices.

The design of optical sensing capsules has been focused on detection of gastrointestinal bleeding using colorimetry ${ }^{152}$, spectroscopy ${ }^{151}$ or fluoroscopy ${ }^{83}$. The colorimetric CE system developed by Qiao et al. ${ }^{152}$ used a huesaturation light color detection method on blood cells selectively channeled into a measurement chamber. This chamber included white LEDs for illumination, a colour sensor and an adsorptive colour-sensitive film that undergoes a change from white to red in the presence of hemoglobin. In vitro trials with different blood concentrations showed that the system could measure hemoglobin concentrations as low as $2.375 \mathrm{mg}$ per $\mathrm{ml}$, which is reported to be less than that found in areas of $\mathrm{GIB}^{153}$.

The wireless spectroscopic HemoPill151 (OVESCO, Tuebingen, Germany) has been tested in a preliminary human trial $^{154}$. The battery-powered capsule is $6.5 \mathrm{~mm}$ in diameter, $25.5 \mathrm{~mm}$ long and contains an optical sensor to measure the optical absorption at $415 \mathrm{~nm}$ between an LED and a photodetector across a recessed channel. At this wavelength optical transmission through blood is at a minimum and is three orders of magnitude less than transmission at a reference wavelength $(720 \mathrm{~nm})$. The optical sensor compares the change in absorption at $415 \mathrm{~nm}$ to the reference signal at $720 \mathrm{~nm}$ to detect haemoglobin. Initial tests were performed on a healthy volunteer with simulated gastrointestinal bleeding under a variety of conditions through periodic ingestion of $20 \mathrm{ml}$ blood. The results were compared with baseline readings from the same volunteer under the same conditions without blood intake. The capsule successfully detected simulated gastrointestinal bleeding after each ingestion of blood, with the detection algorithm showing a correlation $\left(R^{2}=0.9016\right)$ between changing sensor signal within 10 min of capsule ingestion and increased gastric blood concentration.

In 2018, Mimee et al. reported the development of a wireless capsule able to detect gastrointestinal bleeding in a porcine model using genetically engineered bacteria that luminesce in the presence of blood ${ }^{155}$. The Escherichia coli 
bacteria were also modified to enable the detection of thiosulfate and acyl-homoserine lactone, which are potential biomarkers of gut inflammation and infectious bacteria, respectively ${ }^{155}$.

\section{[H3]Gases and volatile organic compounds}

The gut microbiome is a vast community of diverse microorganisms that is important for intestinal homeostasis and is linked to diseases such as IBD and CRC ${ }^{147}$. Direct intraluminal characterization of the microbiome is not possible with current technology. Instead the microbial populations of stool samples are a commonly used proxy of the gut microbiome in clinical research due to the ease of collection. However, studies have shown some difference between fecal and gut microbiomes ${ }^{156}$. Indirect measurement of the microbiome could be achieved by monitoring their metabolic byproducts ${ }^{147}$ as the competition for resources between different microbial populations can lead to deviations in concentrations of by-products of microbial metabolism such as acetic acid, propionic acid and butyric acid, carbon dioxide, hydrogen, methane, ammonia, hydrogen sulfide and volatile fatty acids ${ }^{157}$.

Kalantar-Zadeh et al. developed a wireless CE device that was successfully used to provide real-time measurements of the level of gases such as hydrogen, carbon dioxide and oxygen along the gastrointestinal tract in five human volunteers $^{158}$. The $9.8 \mathrm{~mm}$ diameter, $26 \mathrm{~mm}$ long capsules included a non-specific, semiconducting metal oxide sensor responsive to all oxidizing gases under aerobic and anaerobic conditions. This sensor was calibrated to detect hydrogen, carbon dioxide and oxygen. Intestinal gas entered the capsule through a semi-permeable membrane containing embedded nanoparticles that excluded water. The capsule was capable of operating for more than 4 days, and its excretion could be detected using an onboard temperature sensor. Capsule localization was achieved by measuring oxygen concentration levels throughout the gastrointestinal tract. This localization method successfully detected the gastric, small and large intestinal transit times for solid food. Recording the changing levels of hydrogen provided a means of understanding the microbial fermentation of food in the gut, the anaerobic process by which most small bowel and colonic microbiota obtain energy. However, attempts to correlate the changing levels of gas with diet types and fecal microbiomes of the volunteers were inconclusive. The accuracy of hydrogen and oxygen measurements was better than $0.2 \%$, whereas the accuracy of carbon dioxide measurements was $1 \%$. This capsule was a refinement of a device that had been tested in animal models ${ }^{159,160}$, but previous capsules did not have oxygen and temperature sensors and the algorithm used to determine the gas levels was not as accurate in separating overlapping signals from the hydrogen and carbon dioxide sensors. 
The increasing variety of sensors and imaging technologies adapted for use in conventional and capsule endoscopy is opening up new avenues of research. One area is virtual biopsy, which uses high-resolution transmural imaging technologies to enable in situ, real-time histological examination without the need for a physical biopsy. Virtual biopsy is defined as the ability to make a histological examination by inspection of a site of interest in vivo using specific imaging modalities ${ }^{161}$. Although much of the work done to date has utilized conventional endoscopy because of the wider range of modalities available and absence of miniaturization and integration challenges caused by the space limitations of $\mathrm{CE}^{162-165}$, some efforts that have successfully demonstrated that virtual biopsy is possible in $\mathrm{CE}^{4,98,99}$. Another area of research opened up by the utilization of sensor technology is computer aided diagnosis (CADx) that promises to automate the identification and interpretation of pathology ${ }^{166,167}$. Though these two technologies have demonstrated promising results in laboratory and pre-clinical studies but they are still in their infancy and further work is required to assess the accuracy, sensitivity and specificity of these techniques in CE before they gain wider clinical acceptance.

A technical challenge unique to CE is localization. Currently, commercially available CE devices are passively moved through the GI tract by peristaltic forces and the clinician is unable to control the motion of the capsule or position if an area of interest is observed. The location of the capsule at these sites relative to some known frame of reference is required to enable further treatment or to follow-up with additional observations. Localization of the capsule is the subject of much research in $\mathrm{CE}$, and the following section gives a brief overview of the advantages and disadvantages of some of the methods used.

\section{[H2]Virtual biopsy}

Histological evaluation of tissue obtained from biopsy is a vital part of medical diagnosis. Biopsies can be performed routinely during routine endoscopy through integrated interventional channels. However, capsules are hindered by limited payload capacity, unstable positioning and imprecise capsule/pathology localization. An alternative method to analyse tissue and achieve the same goal as histopathology that could be integrated into future CE devices is virtual biopsy. Theoretical advantages of this method include decreased risk of biopsy-induced adverse events, faster diagnosis and the potential for reduced costs owing to the absence of further tissue processing and pathologic review ${ }^{161,168}$. However, these advantages may be offset by the cost associated with increased surveillance frequency, 
missed detection of a malignant process ${ }^{161}$ and technical challenges such as limited telemetry bandwidth of wireless CE.

Not all imaging modalities are suitable for virtual biopsy in CE. Suitable modalities must be able to acquire subsurface images of a resolution sufficient to view cellular structure within a timeframe of tens of milliseconds ${ }^{168}$ to avoid motion artifacts due to respiration or other causes. This precludes modalities such as WLI CE, as well as chromoendoscopy, endomicroscopy, endocytoscopy as they are limited by the maximum depth of light penetration of $\sim 50 \mu \mathrm{m}^{169}$. Currently, most research into virtual biopsy focuses primarily on OCT, confocal laser endomicroscopy and $\mu$ US. Of these OCT and $\mu$ US have been utilised in CE ${ }^{4,98,99}$. Examples of images obtained with OCT and $\mu$ US are shown in Fig. 2.

OCT is an attractive imaging technology for this application as it is capable of rapid volumetric imaging of mucosal and submucosal structures of the oesophagus in microscopic detail (axial resolution: $\sim 10 \mu \mathrm{m}$, lateral resolution: $\sim 30 \mu \mathrm{m})$ and has been successfully demonstrated in ex vivo and in vivo trials $91,98,170,171$. Various studies using OCT with conventional endoscopy have demonstrated high-resolution volumetric images comparable to those obtained from histology. Furthermore, an accuracy of $92.7 \%$, was reported for the detection of oesophageal carcinoma ${ }^{172}$ and a study of 33 patients with Barrett oesophagus demonstrated accuracy, sensitivity and specificity of $78 \%, 68 \%$ and $82 \%$ respectively for the detection of dysplasia ${ }^{173}$. Initial demonstrations of OCT in CE have thus shown its potential in differentiating between healthy and abnormal tissue ${ }^{98}$. However, many of the current OCT CE devices require further integration and miniaturization to remove the tether to the external illumination source before this technology can be used to image the entire GI tract.

Confocal laser endomicroscopy is slower because it can acquire only one image at a time as it scans through various focal depths, and is therefore not suitable for $\mathrm{CE}^{174}$. Moreover, it has a small field of view, making it impractical to screen large areas of the bowel, and requires exogenous fluorescent markers to ensure good sensitivity ${ }^{91}$ and has not been currently miniaturised for use in CE. As previously noted, $\mu \mathrm{US}$ can image mucosal and transmural pathology, which might enhance its use for virtual biopsy when combined with other diagnostic modalities ${ }^{175}$. This modality has been used in conventional endoscopy through the use of fragile mini-probes that can be inserted into the biopsy channel. These mini-probes can reach frequencies only as high as $30 \mathrm{MHz}$ but results of clinical trials have demonstrated the successfully detection of Barrett oesophagus ${ }^{176}$, oesophageal cancer ${ }^{177}$ and colorectal tumours ${ }^{68}$ 
with accuracies of $88-98 \%, 84 \%$ and $88 \%$ respectively. Initial development of $\mu$ US CE has shown good agreement between the ultrasound image and histology ${ }^{4}$ but further work is needed to verify whether $\mu$ US CE can achieve comparable or superior performance consistently.

Virtual biopsy has been proposed to replace histology in many settings $3,178,179$ when endoscopic imaging technology matures and proficiency with these tools has increased. However, for this to be the case, high accuracy achievable with virtual biopsy methods must be established. In many of the studies published to date, the sensitivities and specificities of virtual biopsy techniques using conventional endoscopy are respectively within $90.0 \%$ and $83.3 \%$ respectively for distinguishing Crohn's disease from ulcerative colitis using $\mathrm{OCT}^{95}$ and within $80-90 \%$ for the detection of lesions ${ }^{180}$. In the latter case, whether such performance is acceptable owing to the risk of cancer development if lesions are missed, is unclear. Additionally, as most of the research on virtual biopsy to date has been done with conventional endoscopy, further work will be needed to verify whether these results are comparable with CE due to the mobile nature of the capsule as well as the effect of increased miniaturization and denser modality integration on the system performance.

\section{[H2]Localization}

CE device localization is defined as knowledge of the position and orientation of the capsule with respect to either gastrointestinal tract anatomy and targets (internal localization) or to external reference systems such as antennas (external localization). This information is essential for accurate capsule navigation and to accurately and reliably map lesions and pathologies in the gastrointestinal tract with respect to internal or external frames of references for diagnosis, treatment and monitoring ${ }^{181,182}$.

Combining pathology detection and classification methodologies, such as the CADx methods discussed in the next section, along with internal and external CE localization not only enables repeated monitoring of the same disease sites but also assists accurate and reliable active locomotion of CE devices, mainly in the case of magneticallydriven, closed-loop navigation in non-rigid environments. The deformability of the gastrointestinal tract requires realtime knowledge of the pose of the capsule with respect to the surrounding unstructured environment, and vice versa. Thus, a hybrid approach, combining internal and external localization, together with autonomous or semiautonomous detection (depending on the accuracy, sensitivity and specificity of the detection method) and classification of pathologies, is required for the next generation of active locomotion capsules and smart endoscopes. 
Autonomous or semi-autonomous detection of pathologies using CE prior to their internal or external localization, is mainly performed using embedded cameras with the support of advanced machine learning techniques ${ }^{183,184}$. Embedding different sensing and imaging modalities into CE is very promising for both robotic control and diagnosis as these methods enable virtual reconstruction of the internal structure of the gastrointestinal tract, potentially improving localization accuracy.

Internal localization of CE is performed mainly through optical imaging techniques, such as lumen reconstructionbased methodologies using sparse or dense depth-reconstruction techniques ${ }^{185}$ or through structured light 3D scanners $^{186}$. It is used primarily to aid navigation of $\mathrm{CE}$, perform direct intervention on diseases and retarget pathological sites for subsequent treatment or follow up. Internal localization is often combined with external localization for computer-aided active capsule locomotion within laboratory prototypes ${ }^{185,187} \mathrm{~A}$ detailed discussion of CE locomotion is available elsewhere ${ }^{185}$.

Current external localization methods such as radio frequency triangulation are integrated in the PillCam systems. Radio frequency localization algorithms are based on triangulation of the telemetry signals emitted by the CE device by external antennae (usually eight) located around the abdomen. This method was experimentally determined to have an average and maximum positional error of $37.7 \mathrm{~mm}$ and $114 \mathrm{~mm}$ respectively ${ }^{188,189}$. Accuracy is low but can be considered adequate for current wireless passive CE devices as they not require additional modules to be integrated and they do not require accurate pose information due to the lack of active motion control.

Several academic teams have focused their research on other external localization techniques based on magnetic field sources that look to be a promising solution for active locomotion of CE devices, as a compromise between integration of components in a small space, computational complexity and overall accuracy. The main advantage of these approaches over other localization methodologies is that low-frequency magnetic signals can pass through human tissue without attenuation, which can be an advantage over radio frequency approaches depending on the frequency ${ }^{190}$; additionally, magnetic sensors do not need line-of-sight vision to detect the capsule. Finally, the position and orientation accuracy of a magnetic-based localization approach is usually superior to that of radio frequency localization methods. For example a study by Taddese et al. ${ }^{191}$ using magnetic-based localization was able to achieve a position and orientation accuracies lower than $5 \mathrm{~mm}$ and $6^{\circ}$ respectively. Magnetic localization 
methods are expected to take the lead over radio frequency approaches when they mature, and new design solutions for capsules with the required integrated sensors are achieved.

\section{[H2]Computer aided diagnosis}

Currently, CE devices can produce up to six frames per second (PillCam SB3, Given Imaging), generating thousands of images during passage through the gastrointestinal tract. Screening of the images can take $0.5-1 \mathrm{hr}$ for a single human reader using high-speed reading techniques ${ }^{192}$, which can lead to between $6 \%-20 \%$ of occurrences of pathology being missed ${ }^{192-195}$. This issue will be exacerbated both by an increase in the number of modalities provided by a capsule and by increased CE usage owing to reduced costs.

Initial approaches to automate aspects of capsule data interpretation using color image analysis to create a suspected blood indicator have been developed. However, reception by the clinical community has been mixed ${ }^{196-198}$ owing to its limited sensitivity and specificity, which one study ${ }^{199}$ has characterized as $56.4 \%$ and $33.5 \%$ respectively.

CADx can be defined as the use of computer algorithms to process and interpret medical data for the purposes of identifying pathology. This approach is relatively new in gastroenterology but similar techniques are widely used in radiology, with several systems already approved by the FDA ${ }^{200}$. Algorithms to automate the detection of lesions ${ }^{201-}$ ${ }^{203}$, ulcers ${ }^{204-206}$, tumours ${ }^{207-211}$ and polyps ${ }^{212}$ from images and video taken with commercial WLI CE devices in the gastrointestinal tract have been reported, with bleeding ${ }^{196-198,213-216}$ receiving most attention as it is often an indication for many GI disorders, such as CRC and Crohn's disease ${ }^{217}$. Some studies have begun to address the identification of more than a single abnormality, with methods reported for simultaneous detection of small bowel ulcers and polyps ${ }^{218}$ and of gastrointestinal bleeding and ulcers ${ }^{219}$. This task is not trivial, as demonstrated in the study by Gan ${ }^{203}$, which illustrated the varying accuracy of an algorithm based on the separation and identification of suspected enteric lesions by their associated colors in correctly identifying different types of enteric lesions because of the complexity and diverse multiformity. Comparing the effectiveness of these proposed methods of CADx to each other in detail is difficult owing to the lack of standardized datasets of CE images. The reported accuracy, sensitivity and specificity of some of the studies found in the literature are shown in Table 4, although accurate comparison of these algorithms is limited due to the lack of standardized data sets. 
1 To date, no studies have been performed on the use of CADx in conjunction with capsule modalities other than WLI because of the limited number of non-WLI CE devices available. However, initial studies on the use of CADx with non-capsule based endoscopy has been conducted using modalities such as $\mathrm{OCT}^{220-222}$, autofluorescence ${ }^{223}$ and $\mathrm{NB}^{224-227}$. A study comprised of 88 patients with 163 lesions to assess the efficacy of color analysis of AFI endoscopy images in the computer-aided differentiation of intramucosal lesions and superficial submucosal cancer from submucosal deep cancer. This method demonstrated sensitivity, specificity and accuracy of $80.0 \%, 84.4 \%$ and $84.1 \%$ respectively 223 . Initial work by Garcia-Allende et al. on excised gastrointestinal tissue found that automated morphological analysis of OCT images had sensitivity, specificity and accuracy as high as $99.7 \%, 99.85 \%$ and $99.88 \%$, respectively, for identifying tumour tissue ${ }^{220}$. Subsequent in vivo studies by Ughi et al. used a tethered capsule-like device to identify Barrett oesophagus on human volunteers. Results showed sensitivity, specificity and accuracy of $94 \%, 93 \%$ and $94 \%$ respectively. However, the study population was limited with one healthy control and two with oesophageal abnormalities ${ }^{221}$. These studies demonstrate that CADx has the potential to be used with specific non-WLI modalities to detect various gastrointestinal pathologies.

Looking ahead, several issues need to be addressed to translate this nascent research in non-white light imaging CE into wider clinical practice (Box 1). Many CE devices are being developed with various imaging and sensing modalities to overcome the limitations of WLI, but these are still in early stages of development with many yet to undergo in vivo animal and human trials. Furthermore, the clinical efficacy of the devices that have been used in humans still needs to be verified as the studies conducted to date are typically limited by small sample sizes. Large clinical trials are required to ascertain the diagnostic yield of these non-WLI capsules for various pathologies.

The specialization of CE, already seen to some extent with WLI CE devices modified to perform better in different parts of the GI tract, will probably continue. By combining multiple modalities within a single device, the diagnostic potential will be increased beyond what can be achieved with single modality devices. A multimodal approach will facilitate both CADx, as already observed with conventional endoscopy, and virtual biopsy by improving accuracy, sensitivity and specificity. However, the combination of modalities for the diagnosis of specific gastrointestinal diseases still needs to be determined. Other technical challenges include improved localization, which is crucial for virtual biopsy to enable accurate, regular monitoring of pathology. 
2

3 This work was supported by the UK Engineering and Physical Sciences Research Council under the Grant 4 EP/K034537/1, entitled Sonopill and by the European Commission within the framework of the endoscopic versatile 5 robotic guidance, diagnosis and therapy of magnetic-driven soft-tethered endoluminal robots Project-H2020-ICT-24-

62015 (EU Project-G.A. number: 688592). The authors wish to acknowledge the support of Mr Vasileios Mitrakos in 7 reviewing this manuscript. 
TABLES 
Table 1: Comparison of Commercially Available Capsule Endoscopes

\begin{tabular}{|c|c|c|c|c|c|c|c|c|c|c|c|}
\hline Model & $\begin{array}{l}\text { Lengt } \\
\mathrm{h} \\
(\mathrm{mm})\end{array}$ & $\begin{array}{l}\text { Diamete } \\
r(\mathrm{~mm})\end{array}$ & $\begin{array}{l}\text { Imagin } \\
\mathrm{g}\end{array}$ & $\begin{array}{l}\text { Fiel } \\
\text { d of } \\
\text { Vie } \\
\text { w }\end{array}$ & Direction & FPS & $\begin{array}{l}\text { Drug } \\
\text { Deliver } \\
\text { y }\end{array}$ & Sensors & $\begin{array}{l}\text { Battery } \\
\text { Life (hrs) }\end{array}$ & $\begin{array}{l}\text { Clinical } \\
\text { Condition }\end{array}$ & Reference \\
\hline \multicolumn{12}{|l|}{ Medtronic } \\
\hline SmartPill & 26 & 13 & NA & NA & NA & NA & No & $\begin{array}{l}\text { Pressure, } \mathrm{pH}, \\
\text { Temperature }\end{array}$ & 120 & $\mathrm{D}$ & 228 \\
\hline BRAVO & & & NA & NA & NA & NA & No & $\mathrm{pH}$ & 48 & GERD & 229 \\
\hline ESO2 & 26 & 11 & CMOS & $312^{\circ}$ & $\begin{array}{l}\text { Front and Back } \\
\text { Viewing }\end{array}$ & 18 & No & NA & 0.5 & GERD,D,BO & $29,30,230$ \\
\hline COLON2 & 32.3 & 11.6 & CMOS & $344^{\circ}$ & $\begin{array}{l}\text { Front and Back } \\
\text { Viewing }\end{array}$ & 4-35 & No & NA & 10 & CRC,IBD & 29,30 \\
\hline UGI & 32.3 & 11.6 & CMOS & $344^{\circ}$ & $\begin{array}{l}\text { Front and Back } \\
\text { Viewing }\end{array}$ & $\begin{array}{l}18- \\
35\end{array}$ & No & NA & 1.5 & OGIB & 231,30 \\
\hline SB & 26 & 11 & CMOS & $140^{\circ}$ & Front Viewing & 2 & No & NA & 8 & OGIB, CD, C & 232,30 \\
\hline SB-2 & 26 & 11 & CMOS & $156^{\circ}$ & Front Viewing & 2 & No & $\mathrm{NA}$ & 9 & OGIB, CD, C & 232,30 \\
\hline SB-3 & 26.2 & 11.4 & CMOS & $156^{\circ}$ & Front Viewing & $2-6$ & No & NA & $11-12$ & OGIB, CD, C & 232,30 \\
\hline \multicolumn{12}{|l|}{ Olympus } \\
\hline EC1 & 26 & 11 & $C C D$ & $145^{\circ}$ & Front Viewing & 2 & No & NA & 8 & $\begin{array}{l}\text { OGIB, IBD, } \\
\text { C,CRC }\end{array}$ & 233,29 \\
\hline EC1-S10 & 26 & 11 & CCD & $160^{\circ}$ & Front Viewing & 2 & No & NA & 12 & $\begin{array}{l}\text { OGIB, IBD, } \\
\text { C,CRC }\end{array}$ & 234,29 \\
\hline \multicolumn{12}{|c|}{ Aquilant Endoscopy } \\
\hline OMOM 2 & 25.4 & 11 & & $140^{\circ}$ & Front Viewing & 2 & No & NA & $6-8$ & OGIB & 235,236 \\
\hline \multicolumn{12}{|c|}{ Capsovision } \\
\hline $\begin{array}{l}\text { Capsoca } \\
\text { m Plus }\end{array}$ & 31 & 11 & CMOS & $360^{\circ}$ & Side Viewing & 20 & No & NA & 15 & OGIB, CD & $\begin{array}{l}230,234,237,23 \\
8 \\
\end{array}$ \\
\hline \multicolumn{12}{|l|}{ Intromedic } \\
\hline MicroCam & 24.5 & 10.8 & & $170^{\circ}$ & Front Viewing & 3 & No & NA & $11-12$ & OGIB & 92,193 \\
\hline \multicolumn{12}{|l|}{ Motilis } \\
\hline MTS2 & 20 & 8 & NA & NA & NA & NA & No & Motility sensor & $\begin{array}{l}\text { Unknow } \\
\text { n }\end{array}$ & $\mathrm{D}$ & 239,240 \\
\hline
\end{tabular}




\begin{tabular}{|c|c|c|c|c|c|c|c|c|c|c|c|}
\hline \multicolumn{12}{|l|}{ Ovesco } \\
\hline Hemopill & 25.5 & 615 & NA & NA & NA & NA & No & Optical blood sensor & $\begin{array}{l}\text { Unknow } \\
\mathrm{n}\end{array}$ & OGIB & 154 \\
\hline \multicolumn{12}{|c|}{ Medimetrics } \\
\hline Intellicap & 27 & 11 & NA & NA & NA & NA & Yes & $\mathrm{pH}$, Temperature & 48 & DD & 241 \\
\hline
\end{tabular}

BO- Barrett oesophagus, C- Coeliac Disease, CD - Crohn's Disease, CRC- Colorectal Cancer, D - Dysmotility, DD- Drug Delivery, GERD- Gastroesophageal Reflux Disease, NA - Not applicable, OGIB - Obscure Gastrointestinal Bleeding 
Table 2: Summary of guidance on the use of CE

\begin{tabular}{|c|c|c|c|c|c|c|}
\hline \multirow[b]{2}{*}{ Pathology } & \multicolumn{3}{|c|}{ European Society of Gastrointestinal Endoscopy ${ }^{7242}$} & \multicolumn{3}{|c|}{ American Gastroenterology Association 6} \\
\hline & Key guidance on the use of CE & $\begin{array}{l}\text { Recommen } \\
\text { dation }\end{array}$ & $\begin{array}{c}\text { Evidence } \\
\text { quality }\end{array}$ & Key guidance on the use of CE & $\begin{array}{c}\text { Recommend } \\
\text { ation }\end{array}$ & $\begin{array}{c}\text { Evidence } \\
\text { quality }\end{array}$ \\
\hline \multirow[b]{2}{*}{ OGIB } & \multirow[b]{2}{*}{ First-line for investigation of OGIB. } & \multirow[b]{2}{*}{ Strong } & \multirow[b]{2}{*}{ Moderate } & $\begin{array}{l}\text { Perform CE as soon as possible } \\
\text { for overt, OGIB episode. }\end{array}$ & Strong & Very low \\
\hline & & & & $\begin{array}{c}\text { Recommended for selected cases } \\
\text { with OGIB and unexplained mild } \\
\text { chronic IDA. }\end{array}$ & Strong & Low \\
\hline IDA & $\begin{array}{l}\text { First-line for (IDA) following } \\
\text { inconclusive results from } \\
\text { conventional endoscopy. }\end{array}$ & Strong & Moderate & \multicolumn{3}{|c|}{ Included under OGIB } \\
\hline $\begin{array}{l}\text { Small } \\
\text { bowel } \\
\text { tumour }\end{array}$ & $\begin{array}{l}\text { Recommended when OGIB and IDA } \\
\text { are unexplained. }\end{array}$ & Strong & Moderate & NA & NA & NA \\
\hline $\begin{array}{l}\text { Polyposis } \\
\text { syndrome } \\
\quad \text { s }\end{array}$ & $\begin{array}{c}\text { For surveillance of small bowel in } \\
\text { patients with Familial adenomatous } \\
\text { polyposis and Peutz-Jeghers } \\
\text { syndrome. }\end{array}$ & Strong & Moderate & $\begin{array}{l}\text { For ongoing surveillance of small } \\
\text { bowel in patients with polyposis } \\
\text { syndromes. }\end{array}$ & Conditional & Very low \\
\hline $\begin{array}{l}\text { Coeliac } \\
\text { disease }\end{array}$ & $\begin{array}{l}\text { Not recommended for suspected } \\
\text { coeliac disease. Can be considered } \\
\text { in patients unable or unwilling to } \\
\text { undergo conventional endoscopy. }\end{array}$ & Strong & Low & $\begin{array}{l}\text { Not recommended for suspected } \\
\text { coeliac disease. Can be } \\
\text { considered in patients unable or } \\
\text { unwilling to undergo conventional } \\
\text { endoscopy. }\end{array}$ & Strong & Very low \\
\hline $\begin{array}{l}\text { Crohn's } \\
\text { disease }\end{array}$ & $\begin{array}{l}\text { Recommended for suspected } \\
\text { Crohn's disease with negative } \\
\text { ileocolonoscopy findings and } \\
\text { absence of obstructive symptoms. }\end{array}$ & Strong & Moderate & $\begin{array}{l}\text { Recommended for suspected } \\
\text { Crohn's disease with negative } \\
\text { ileocolonoscopy findings and } \\
\text { absence of obstructive symptoms. }\end{array}$ & Strong & Very low \\
\hline $\begin{array}{l}\text { colorectal } \\
\text { cancer }\end{array}$ & $\begin{array}{l}\text { CE can be considered in patients for } \\
\text { whom conventional endoscopy is } \\
\text { inappropriate or not possible. }\end{array}$ & Grade D* & Level 4 & $\begin{array}{l}\text { CE can be considered in patients } \\
\text { for whom conventional endoscopy } \\
\text { is inappropriate or not possible. }\end{array}$ & Strong & Very low \\
\hline
\end{tabular}

Reporting of recommendation follows the GRADE approach ${ }^{243}$. ${ }^{*}$ Recommendation for colorectal cancer grading uses the amended SIGN system ${ }^{244}$. OGIB, obscure gastrointestinal bleeding; IDA, iron deficiency anemia; CE, capsule endoscopy; 
Table 3: Development stage of capsule endoscopes of various diagnostic and imaging modalities

\begin{tabular}{|c|c|c|c|}
\hline Sensing modality & Technical progress & $\begin{array}{c}\text { Primary intended location of use in gastrointestinal } \\
\text { tract }\end{array}$ & Refs \\
\hline White light imaging & In clinical use & Entire tract & $29,232,231,233,234,235234,245,246$ \\
\hline $\begin{array}{l}\text { Non-white light, } \\
\text { optical imaging (NBI, } \\
\text { chromoendoscopy) }\end{array}$ & In clinical use & Entire tract & $52-55$ \\
\hline $\mathrm{pH}$ & In clinical use & Entire tract & $136,228,229,241$ \\
\hline Temperature & In clinical use & Entire tract & $107,108,228,241$ \\
\hline Biomarkers & $\begin{array}{l}\text { In vivo human trials (Ovesco } \\
\text { Hemopill) } \\
\text { In vitro trials (all others) }\end{array}$ & Stomach (Ovesco device) & 148-152 \\
\hline Electrophysiology & Ex vivo trials & Small Bowel & 127 \\
\hline Fluorescent imaging & Ex vivo trials & $\begin{array}{l}\text { Small Bowel (Demosthenous device) } \\
\text { Stomach (Nemiroski device) }\end{array}$ & $81,82,83$ \\
\hline Gas sensing & In vivo, human trials & Large Intestine & $158-160$ \\
\hline Ionizing radiation & In vivo, human trials & Large Intestine & $103,104,102$ \\
\hline Manometry & In vivo, human trials & Entire tract & 228 \\
\hline $\begin{array}{l}\text { Optical coherence } \\
\text { tomography }\end{array}$ & In vivo, human trials & Oesophagus & 98,99 \\
\hline Ultrasonography & In vivo, animal trials & $\begin{array}{l}\text { Small Bowel (Sonopill device) } \\
\text { Entire tract (Stanford device) }\end{array}$ & $60,61,62,63,64$ \\
\hline
\end{tabular}

$\mathrm{NBI}$, narrow band imaging 
Table 4: Accuracy, sensitivity and specificity of in vivo, computer aided diagnosis for human gastrointestinal pathologies using capsule endoscopy

\begin{tabular}{|c|c|c|c|c|c|c|c|}
\hline Pathology & $\begin{array}{l}\text { Total } \\
\text { number } \\
\text { of } \\
\text { images } \\
\text { in } \\
\text { dataset }\end{array}$ & $\begin{array}{l}\text { Number of } \\
\text { images in } \\
\text { dataset } \\
\text { with } \\
\text { pathology }\end{array}$ & Sensitivity & Specificity & Accuracy & Year & Reference \\
\hline \multicolumn{8}{|l|}{ Bleeding } \\
\hline & 5000 & 1000 & $99.00 \%$ & $94.00 \%$ & $95.00 \%$ & 2014 & 213 \\
\hline & 607 & 220 & $93.84 \%$ & NR & $92.86 \%$ & 2014 & 214 \\
\hline & 100 & 45 & $82.30 \%$ & $89.10 \%$ & NR & 2012 & 215 \\
\hline & 100 & 50 & $80.00 \%$ & $95.30 \%$ & $94.40 \%$ & 2014 & 198 \\
\hline & 2400 & 400 & $92.00 \%$ & $96.50 \%$ & $95.75 \%$ & 2016 & 216 \\
\hline & 1200 & 600 & $99.41 \%$ & $98.95 \%$ & $99.19 \%$ & 2015 & 197 \\
\hline & 7648 & 1933 & $92.32 \%$ & $95.07 \%$ & $94.50 \%$ & 2018 & 196 \\
\hline \multicolumn{8}{|c|}{ Inflammatory and Vascular Lesions } \\
\hline & 137 & 77 & $95.01 \%$ & $83.02 \%$ & $89.01 \%$ & 2014 & 202 \\
\hline \multicolumn{8}{|c|}{ Common lesions and Angioectasia } \\
\hline & 52374 & 4156 & $\begin{array}{ll}78.6 & - \\
9.4 \% & \\
\end{array}$ & $\begin{array}{l}92.1 \%- \\
30.5 \%\end{array}$ & $\begin{array}{l}91.3 \%- \\
35.7 \%\end{array}$ & 2008 & 203 \\
\hline \multicolumn{8}{|l|}{ Polyps } \\
\hline & 18968 & 230 & $47.4 \%$ & $90.2 \%$ & NR & 2013 & 212 \\
\hline \multicolumn{8}{|l|}{ Ulcers } \\
\hline & 160 & 80 & $82.50 \%$ & $100 \%$ & $91.25 \%$ & 2009 & 204 \\
\hline & 260 & 130 & $84.51 \%$ & $88.56 \%$ & $86.54 \%$ & 2013 & 205 \\
\hline & 137 & 65 & $96.62 \%$ & $91.67 \%$ & $94.16 \%$ & 2015 & 206 \\
\hline \multicolumn{8}{|l|}{ Tumour } \\
\hline & 120 & 60 & $88.60 \%$ & $96.20 \%$ & $92.40 \%$ & 2012 & 207 \\
\hline & 1200 & 600 & $92.33 \%$ & $88.67 \%$ & $90.50 \%$ & 2011 & 211 \\
\hline & 1800 & 900 & $97.80 \%$ & $96.70 \%$ & $97.30 \%$ & 2016 & 208 \\
\hline & 3000 & 700 & $93.90 \%$ & $93.10 \%$ & NR & 2012 & 209 \\
\hline & 600 & 200 & $97.20 \%$ & $97.40 \%$ & NR & 2009 & 210 \\
\hline
\end{tabular}

NR, not reported 
FIGURES
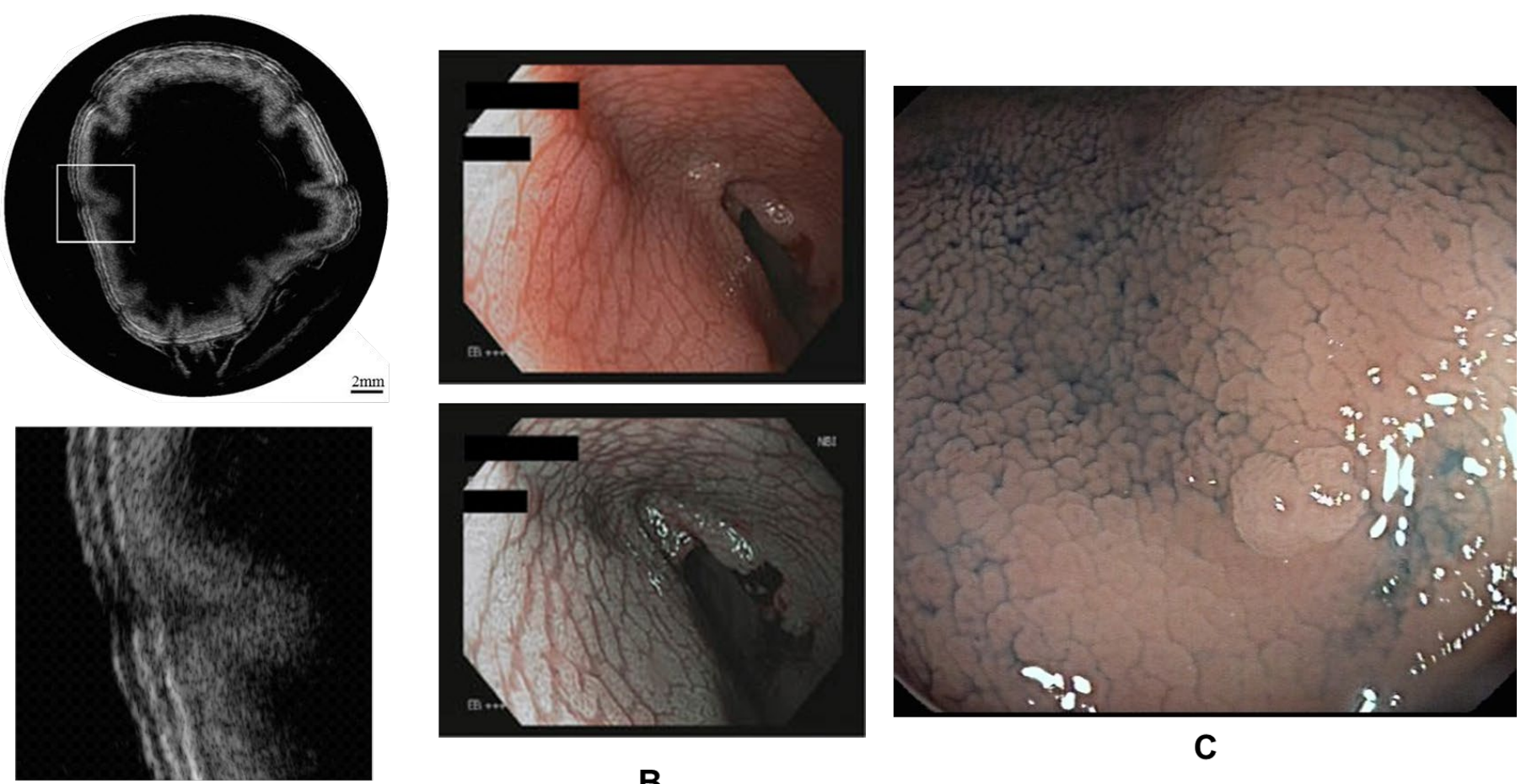

B

C

A

Fig. 1 Examples of images obtained using alternative imaging technologies. a | In-Vitro imaging of porcine bowel using $39 \mathrm{MHz}$ ultrasound capsule endoscope ${ }^{61}$. b | Images of the duodenum in coeliac disease. The top panel was obtained using white light imaging and the bottom panel was obtained using narrow band imaging. Images courtesy of E. Toth. C | Image of polyps obtained using dye chromoendoscopy using $0.2 \%$ indigo carmine. Image courtesy of A. Koulaouzidis 


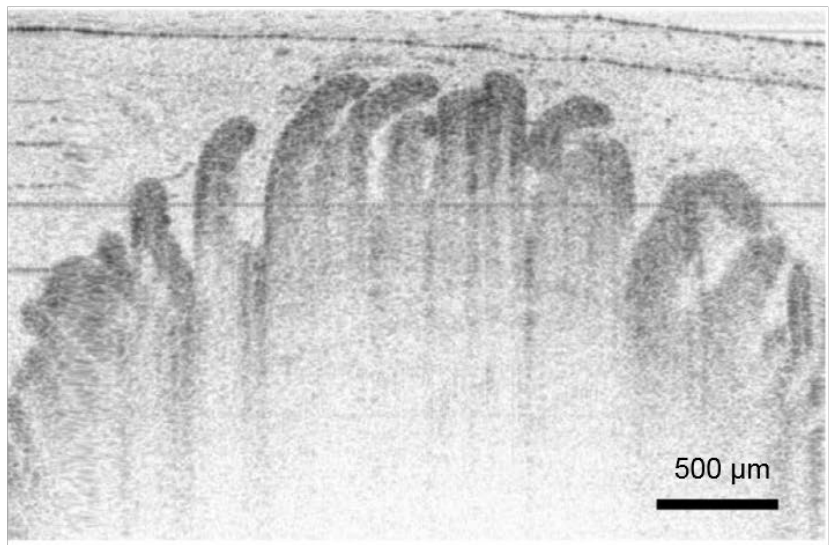

\section{A}
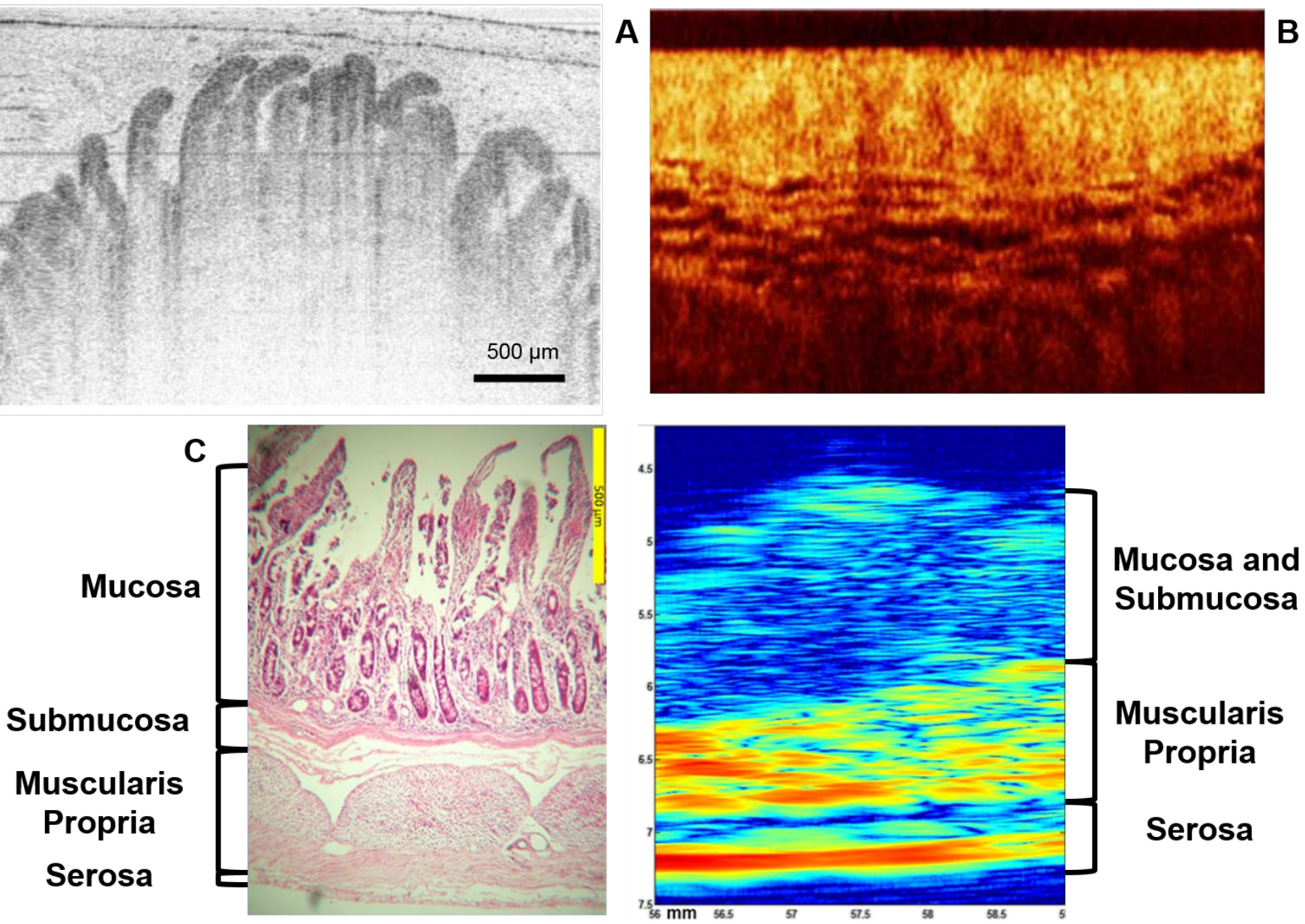

Mucosa and

Submucosa

Muscularis

Propria

Serosa

Fig. 2 Modalities for virtual biopsy. a | Cross-sectional image of intestinal villi captured using optical coherence tomograpy ${ }^{93}$. b | OCT image of hyperplastic polyp ${ }^{171}$. c | A slide of haemotoxylin and eosin-stained porcine small bowel, which shows good agreement with a $47 \mathrm{MHz}$ micro-ultrasound scan of fresh frozen porcine bowel tissue ${ }^{72}$ 
Box 1

- White light imaging capsule endoscopy is limited to surface visualization and limited specificity of diagnosis due to similarities in the mucosal appearance of different small bowel diseases.

- Research and development of non-white light imaging capsules has increased in recent years.

- Some of these non-WLI capsules are now commercially available, such as the SmartPill.

- Most of the non-WLI capsules are still at the prototype stage, and the diagnostic efficacy of their sensing and imaging modalities, as well as their cost-benefit ratio needs to be validated through extensive clinical trials.

- Non-WLI capsules capable of measuring pH, pressure changes, concentration of chemicals and much more have been developed.

- One challenge of WLI and non-WLI CE is the need for accurate means of determining the position of the capsule at all times to enable the localization of pathologies for subsequent follow-up.

- Non-WLI capsules such as those capable of OCT or micro-ultrasound have the potential to provide CE with the capability of providing real-time, in vivo, high-resolution transmural imaging that could remove the need for tissue biopsy.

- One challenge for clinicians in the future will be the increasing amount of data that will need to be reviewed for diagnosis due to the increased use of WLI and non-WLI CE.

- This challenge has spurred research into computer aided diagnosis (CADx), whereby algorithms are used to automate the identification and interpretation of pathologies

- The lack of standardized data-sets has impeded the accurate comparison of various CADx algorithms.

- CADx may require the use of multiple modalities in non-WLI CE to improve accuracy and specificity, which will require challenges related to miniaturization, integration and power consumption of CE systems to be overcome. 


\section{GLOSSARY}

Compton Scattering: The scattering of a photon by a charge particle that results in a decrease in energy of the photon. Cyclic Voltammetry: A type of voltammetric experiment where the potential is varied as a linear function of time. It is one of the most commonly used electrochemical techniques.

Micro-cancers

Photobleaching: The permanent loss of fluorescence in a fluorophore due to photon-induced chemical damage

Potentiostatic circuit: An electronic circuit that enables the control of the voltage difference between electrodes in an electrochemical cell.

Pulse Voltammetry: A type of voltammetric experiment where the varying potential consists of a series of increasing amplitude, with the potential returning to the initial value after each pulse.

Quantum yield: Quantum yield refers to the number of times a specific event occurs per photon absorbed by the system in a radiation induced process.

Single element transducer: A device that generally consists of a piezoelectric material housed in a casing that can both transmit and receive ultrasound signals.

Voltammetry: An electrochemical experiment used to identify a substance by how the current flowing through it changes as the potential is changed.

Voltammograms: A plot of cell current versus. the potential arising from a Voltammetry experiment

Volumetric Imaging: A sequence of 2D images that are grouped together to form a 3D image of a volume of space 


\section{REFERENCES}

1. Enns, R. A. et al. Clinical Practice Guidelines for the Use of Video Capsule Endoscopy. Gastroenterology 152 , 497-514 (2017).

2. Koulaouzidis, A., lakovidis, D. K., Karargyris, A. \& Rondonotti, E. Wireless endoscopy in 2020: Will it still be a capsule? World J. Gastroenterol. 21, 5119-5130 (2015).

3. Cox, B. F. B. F. et al. Ultrasound capsule endoscopy: sounding out the future. Ann. Transl. Med. 5, 201-201 (2017).

4. Lay, H. et al. In-Vivo Evaluation of Microultrasound and Thermometric Capsule Endoscopes. IEEE Trans. Biomed. Eng. 66, 632-639 (2018).

5. Zhang, H. et al. Biochromoendoscopy: molecular imaging with capsule endoscopy for detection of adenomas of the GI tract. Gastrointest. Endosc. 68, 520-527 (2008).

6. Enns, R. A. et al. Clinical Practice Guidelines for the Use of Video Capsule Endoscopy. Gastroenterology 152, 497-514 (2017).

7. Pennazio, M. et al. Small-bowel capsule endoscopy and device-assisted enteroscopy for diagnosis and treatment of small-bowel disorders: European Society of Gastrointestinal Endoscopy (ESGE) Clinical Guideline. Endoscopy 47, 352-386 (2015).

8. Bruaene, C. Van de. Small bowel capsule endoscopy: Where are we after almost 15 years of use? World J. Gastrointest. Endosc. (2015). doi:10.4253/wjge.v7.i1.13

9. Nowak, T. A global perspective on capsule endoscopy. Ann. Transl. Med. 5, 422-422 (2017).

10. Romero-Vázquez, J. et al. Capsule endoscopy in patients refusing conventional endoscopy. World Journal of Gastroenterology (2014). doi:10.3748/wjg.v20.i23.7424

11. Triester, S. L. et al. A Meta-Analysis of the Yield of Capsule Endoscopy Compared to Other Diagnostic Modalities in Patients with Obscure Gastrointestinal Bleeding. Am. J. Gastroenterol. 100, 2407-2418 (2005).

12. Teshima, C. W., Kuipers, E. J., van Zanten, S. V. \& Mensink, P. B. F. Double balloon enteroscopy and capsule endoscopy for obscure gastrointestinal bleeding: An updated meta-analysis. J. Gastroenterol. Hepatol. 26, 796-801 (2011).

13. Kaffes, A. J., Siah, C. \& Koo, J. H. Clinical outcomes after double-balloon enteroscopy in patients with obscure GI bleeding and a positive capsule endoscopy. Gastrointest. Endosc. 66, 304-309 (2007).

14. Otani, K. et al. Clinical Utility of Capsule Endoscopy and Double-Balloon Enteroscopy in the Management of Obscure Gastrointestinal Bleeding. Digestion 97, 52-58 (2018).

15. Ludvigsson, J. F. et al. Diagnosis and management of adult coeliac disease: Guidelines from the British society of gastroenterology. Gut (2014). doi:10.1136/gutjnl-2013-306578

16. Chang, M. S., Rubin, M., Lewis, S. K. \& Green, P. H. Diagnosing celiac disease by video capsule endoscopy (VCE) when esophogastroduodenoscopy (EGD) and biopsy is unable to provide a diagnosis: a case series. BMC Gastroenterol. 12, 90 (2012).

17. Hopper, A., Cross, S. \& Sanders, D. Patchy villous atrophy in adult patients with suspected gluten-sensitive enteropathy: is a multiple duodenal biopsy strategy appropriate? Endoscopy 40, 219-224 (2007).

18. Rubio-Tapia, A. et al. ACG clinical guidelines: diagnosis and management of celiac disease. Am. J. Gastroenterol. (2013). doi:10.1038/ajg.2013.79

19. Dionisio, P. M. et al. Capsule Endoscopy Has a Significantly Higher Diagnostic Yield in Patients With Suspected and Established Small-Bowel Crohn's Disease: A Meta-Analysis. Am. J. Gastroenterol. 105, 1240$1248(2010)$.

20. Jensen, M. D., Nathan, T., Rafaelsen, S. R. \& Kjeldsen, J. Diagnostic Accuracy of Capsule Endoscopy for Small Bowel Crohn's Disease Is Superior to That of MR Enterography or CT Enterography. Clin. Gastroenterol. Hepatol. 9, 124-129.e1 (2011).

21. González-Suárez, B. et al. Comparison of Capsule Endoscopy and Magnetic Resonance Enterography for the Assessment of Small Bowel Lesions in Crohn's Disease. Inflamm. Bowel Dis. 24, 775-780 (2018).

22. Panes, J. et al. Imaging techniques for assessment of inflammatory bowel disease: Joint ECCO and ESGAR evidence-based consensus guidelines. J. Crohn's Colitis 7, 556-585 (2013).

23. Niv, Y. Small-bowel mucosal healing assessment by capsule endoscopy as a predictor of long-term clinical remission in patients with Crohn's disease. Eur. J. Gastroenterol. Hepatol. 29, 844-848 (2017).

24. Koulaouzidis, A. \& Plevris, J. N. Detection of the ampulla of Vater in small bowel capsule endoscopy: Experience with two different systems. J. Dig. Dis. 13, 621-627 (2012).

25. Friedrich, K., Gehrke, S., Stremmel, W. \& Sieg, A. First clinical trial of a newly developed capsule endoscope with panoramic side view for small bowel: A pilot study. J. Gastroenterol. Hepatol. 28, 1496-1501 (2013).

26. Akin, E. et al. Comparison between Capsule Endoscopy and Magnetic Resonance Enterography for the Detection of Polyps of the Small Intestine in Patients with Familial Adenomatous Polyposis. Gastroenterol. 
Res. Pract. 2012, 1-5 (2012).

27. Burke, C. A., Santisi, J., Church, J. \& Levinthal, G. The Utility of Capsule Endoscopy Small Bowel Surveillance in Patients with Polyposis. Am. J. Gastroenterol. 100, 1498-1502 (2005).

28. Cairns, S. R. et al. Guidelines for colorectal cancer screening and surveillance in moderate and high risk groups (update from 2002). Gut 59, 666-689 (2010).

29. Kurniawan, N. \& Keuchel, M. Technology. in Video Capsule Endoscopy 15-20 (Springer Berlin Heidelberg, 2014). doi:10.1007/978-3-662-44062-9_3

30. McAlindon, M. E., Hagenmüller, F. \& Fleischer, D. E. Fields of Application. in Video Capsule Endoscopy 5-13 (Springer Berlin Heidelberg, 2014). doi:10.1007/978-3-662-44062-9_2

31. Spada, C. et al. Accuracy of First- and Second-Generation Colon Capsules in Endoscopic Detection of Colorectal Polyps: A Systematic Review and Meta-analysis. Clin. Gastroenterol. Hepatol. 14, 1533-1543.e8 (2016).

32. Sharma, V. K., Eliakim, R., Sharma, P. \& Faigel, D. ICCE Consensus for Esophageal Capsule Endoscopy. Endoscopy 37, 1060-1064 (2005).

33. Eliakim, R. et al. A Prospective Study of the Diagnostic Accuracy of PillCam ESO Esophageal Capsule Endoscopy Versus Conventional Upper Endoscopy in Patients With Chronic Gastroesophageal Reflux Diseases. J. Clin. Gastroenterol. 39, 572-578 (2005).

34. Park, J., Cho, Y. K. \& Kim, J. H. Current and Future Use of Esophageal Capsule Endoscopy. Clin. Endosc. 51, 317-322 (2018).

35. Koprowski, R. Overview of technical solutions and assessment of clinical usefulness of capsule endoscopy. Biomed. Eng. Online 14, 111 (2015).

36. Mustafa, B. F., Samaan, M., Langmead, L. \& Khasraw, M. Small bowel video capsule endoscopy: an overview. Expert Rev. Gastroenterol. Hepatol. 7, 323-329 (2013).

37. McAlindon, M. E., Sanders, D. S. \& Sidhu, R. Capsule endoscopy: 10 years on and in the frontline. Frontline Gastroenterol. 1, 82-87 (2010).

38. Hong, S. P., Cheon, J. H., Kim, T. II, Song, S. Y. \& Kim, W. H. Comparison of the diagnostic yield of 'MiroCam' and 'PillCam SB' capsule endoscopy. Hepatogastroenterology. 59, 778-81 (2012).

39. Hartmann, D., Eickhoff, A., Damian, U. \& Riemann, J. F. Diagnosis of small-bowel pathology using paired capsule endoscopy with two different devices: a randomized study. Endoscopy 39, 1041-5 (2007).

40. Kim, H. M. et al. A Pilot Study of Sequential Capsule Endoscopy Using MiroCam and PillCam SB Devices with Different Transmission Technologies. Gut Liver 4, 192-200 (2010).

41. Rahman, M. et al. Comparison of the diagnostic yield and outcomes between standard $8 \mathrm{~h}$ capsule endoscopy and the new $12 \mathrm{~h}$ capsule endoscopy for investigating small bowel pathology. World $\mathrm{J}$. Gastroenterol. 21, 5542-7 (2015).

42. Ou, G. et al. Effect of longer battery life on small bowel capsule endoscopy. World J. Gastroenterol. 21, 2677$82(2015)$.

43. Cave, D. R. et al. A multicenter randomized comparison of the Endocapsule and the Pillcam SB. Gastrointest. Endosc. 68, 487-94 (2008).

44. New Challenges in Gastrointestinal Endoscopy. (Springer Japan, 2008). doi:10.1007/978-4-431-78889-8

45. Xavier, R. J. P. D. K. Unravelling the pathogenesis of inflammatory bowel disease. Nature 448, 427-434 (2007).

46. Ciaccio, E. J., Bhagat, G., Lewis, S. K. \& Green, P. H. Suggestions for automatic quantitation of endoscopic image analysis to improve detection of small intestinal pathology in celiac disease patients. Comput. Biol. Med. 65, 364-368 (2015).

47. Dickson, B. C., Streutker, C. J. \& Chetty, R. Coeliac disease: an update for pathologists. J. Clin. Pathol. 59, 1008-16 (2006).

48. Kav, T. \& Sivri, B. Is enteroscopy necessary for diagnosis of celiac disease? World J. Gastroenterol. 18, 4095-101 (2012).

49. Har-Noy, O. et al. Chromoendoscopy, Narrow-Band Imaging or White Light Endoscopy for Neoplasia Detection in Inflammatory Bowel Diseases. Dig. Dis. Sci. 62, 2982-2990 (2017).

50. Hoffman, A., Manner, H., Rey, J. W. \& Kiesslich, R. A guide to multimodal endoscopy imaging for gastrointestinal malignancy - an early indicator. Nat. Rev. Gastroenterol. Hepatol. 14, 421-434 (2017).

51. Kaltenbach, T. Nonpolypoid Colorectal Neoplasms in Inflammatory Bowel Disease. (Elsevier, 2014).

52. Khan, T. H., Shrestha, R., Wahid, K. A. \& Babyn, P. Design of a smart-device and FPGA based wireless capsule endoscopic system. Sensors Actuators A Phys. 221, 77-87 (2015).

53. Khan, T. H. \& Wahid, K. A. White and narrow band image compressor based on a new color space for capsule endoscopy. Signal Process. Image Commun. 29, 345-360 (2014).

54. Krystallis, C., Koulaouzidis, A., Douglas, S. \& Plevris, J. N. Chromoendoscopy in small bowel capsule endoscopy: Blue mode or Fuji Intelligent Colour Enhancement? Dig. Liver Dis. 43, 953-957 (2011).

55. Imagawa, H. et al. Improved visibility of lesions of the small intestine via capsule endoscopy with computed 
virtual chromoendoscopy. Gastrointest. Endosc. 73, 299-306 (2011).

56. Giacchino, M. et al. Clinical utility and interobserver agreement of autofluorescence imaging and magnification narrow-band imaging for the evaluation of Barrett's esophagus: A prospective tandem study. Gastrointest. Endosc. 77, 711-718 (2013).

57. Silva, F. B. et al. Endoscopic assessment and grading of Barrett's esophagus using magnification endoscopy and narrow-band imaging: Accuracy and interobserver agreement of different classification systems (with videos). Gastrointest. Endosc. 73, 7-14 (2011).

58. Pasha, S. F. et al. Comparison of the Yield and Miss Rate of Narrow Band Imaging and White Light Endoscopy in Patients Undergoing Screening or Surveillance Colonoscopy: A Meta-Analysis. Am. J. Gastroenterol. 107, 363-370 (2012).

59. Singh, R. et al. Multicenter randomised controlled trial comparing the high definition white light endoscopy and the bright narrow band imaging for colon polyps. World J. Gastrointest. Endosc. 9, 273 (2017).

60. Memon, F. et al. Capsule ultrasound device: Further developments. in 2016 IEEE International Ultrasonics Symposium (IUS) 1-4 (IEEE, 2016). doi:10.1109/ULTSYM.2016.7728851

61. Wang, X. et al. Development of a Mechanical Scanning Device With High-Frequency Ultrasound Transducer for Ultrasonic Capsule Endoscopy. IEEE Trans. Med. Imaging 36, 1922-1929 (2017).

62. Lay, H. S. et al. Translational trial outcomes for capsule endoscopy test devices. in 2017 IEEE International Ultrasonics Symposium (IUS) 1-4 (IEEE, 2017). doi:10.1109/ULTSYM.2017.8091826

63. Correia, J. TROY: Endoscope Capsule Using Ultrasound Technology, Final Report. INSTITUTO AGILUS DE INOVAÇAO EM TECNOLOGIAS DE INFORMAÇAO S.A MATOSINHOS (2009).

64. Lee, J. H. et al. Towards wireless capsule endoscopic ultrasound (WCEU). in 2014 IEEE International Ultrasonics Symposium 734-737 (IEEE, 2014). doi:10.1109/ULTSYM.2014.0181

65. Chang, C. et al. Singulation for imaging ring arrays of capacitive micromachined ultrasonic transducers. J. Micromechanics Microengineering 24, 107002 (2014).

66. Lay, H. S., Cox, B. F., Seetohul, V., Demore, C. E. M. \& Cochran, S. Design and Simulation of a Ring-Shaped Linear Array for Microultrasound Capsule Endoscopy. IEEE Trans. Ultrason. Ferroelectr. Freq. Control 65, 589-599 (2018).

67. McNally, P. R. Endoscopic Ultrasound. in Gl/Liver Secrets (ed. McNally, P. R.) 537-544 (Elsevier, 2010). doi:10.1016/B978-0-323-06397-5.00072-1

68. Gall, T. M. H., Markar, S. R., Jackson, D., Haji, A. \& Faiz, O. Mini-probe ultrasonography for the staging of colon cancer: a systematic review and meta-analysis. Color. Dis. 16, O1-O8 (2014).

69. Hünerbein, M., Handke, T., Ulmer, C. \& Schlag, P. M. Impact of miniprobe ultrasonography on planning of minimally invasive surgery for gastric and colonic tumors. Surgical Endoscopy and Other Interventional Techniques (2004). doi:10.1007/s00464-003-8925-z

70. Hurlstone, D. P., Brown, S., Cross, S. S., Shorthouse, A. J. \& Sanders, D. S. Endoscopic ultrasound miniprobe staging of colorectal cancer: Can management be modified? Endoscopy (2005). doi:10.1055/s2005-870142

71. Schembre, D., Ayub, K. \& Jiranek, G. High-Frequency Mini-Probe Ultrasound: The Rodney Dangerfield of Endoscopy? J. Clin. Gastroenterol. 39, 555-556 (2005).

72. Cox, B. F., Seetohul, V., Lay, H. \& Cochran, S. Microultraound and small bowel inflammation: Tissue phantom studies. in 2015 IEEE International Ultrasonics Symposium (IUS) 1-4 (IEEE, 2015). doi:10.1109/ULTSYM.2015.0304

73. Strobel, D., Goertz, R. S. \& Bernatik, T. Diagnostics in inflammatory bowel disease: Ultrasound. World J. Gastroenterol. 17, 3192-3197 (2011).

74. Huang, Z. et al. Laser-induced autofluorescence microscopy of normal and tumor human colonic tissue. Int. J. Oncol. 24, 59-63 (2004).

75. Moriichi, K. et al. Back-to-Back Comparison of Auto-Fluorescence Imaging (AFI) Versus High Resolution White Light Colonoscopy for Adenoma Detection. BMC Gastroenterol. 12, (2012).

76. Zhao, Z.-Y. et al. Detection and miss rates of autofluorescence imaging of adenomatous and polypoid lesions during colonoscopy: a systematic review and meta-analysis. Endosc. Int. Open 3, E226-E235 (2015).

77. Moriichi, K., Fujiya, M. \& Okumura, T. The efficacy of autofluorescence imaging in the diagnosis of colorectal diseases. Clin. J. Gastroenterol. 9, 175-83 (2016).

78. Fujiya, M., Saitoh, Y., Watari, J., Moriichi, K. \& Kohgo, Y. Autofluorescence imaging is useful to assess activity of ulcerative colitis. Dig. Endosc. 19, 145-149 (2007).

79. Osada, T. et al. Autofluorescence imaging endoscopy for identification and assessment of inflammatory ulcerative colitis. World J. Gastroenterol. 17, 5110-5116 (2011).

80. Moriichi, K. et al. Quantification of autofluorescence imaging can accurately and objectively assess the severity of ulcerative colitis. Int. J. Colorectal Dis. 30, 1639-1643 (2015).

81. Al-Rawhani, M. A., Beeley, J. \& Cumming, D. R. S. Wireless fluorescence capsule for endoscopy using single photon-based detection. Sci. Rep. 5, 18591 (2015). 
82. Demosthenous, P., Pitris, C. \& Georgiou, J. Infrared Fluorescence-Based Cancer Screening Capsule for the Small Intestine. IEEE Trans. Biomed. Circuits Syst. 10, 467-476 (2016).

83. Nemiroski, A., Ryou, M., Thompson, C. C. \& Westervelt, R. M. Swallowable fluorometric capsule for wireless triage of gastrointestinal bleeding. Lab Chip 15, 4479-4487 (2015).

84. Baier, J. et al. Singlet oxygen generation by UVA light exposure of endogenous photosensitizers. Biophys. J. 91, 1452-1459 (2006).

85. Inayama, K. et al. Basic study of an agent for reinforcement of near-infrared fluorescence on tumor tissue. Dig. Liver Dis. 35, 88-93 (2003).

86. Ito, S. et al. Principle and clinical usefulness of the infrared fluorescence endoscopy. J Med Invest 53, 1-8 (2006).

87. Urbanska, K. et al. Indocyanine green as a prospective sensitizer for photodynamic therapy of melanomas. Acta Biochim. Pol. 49, 387-391 (2002).

88. MUGURUMA, N. et al. Labeled Carcinoembryonic Antigen Antibodies Excitable by Infrared Rays. A Novel Diagnostic Method for Micro Cancers in the Digestive Tract. Intern. Med. 38, 537-542 (1999).

89. Tadatsu, M. et al. A new infrared fluorescent-Labeling agent and labeled antibody for diagnosing microcancers. Bioorg. Med. Chem. 11, 3289-3294 (2003).

90. Wagnières, G. A., Star, W. M. \& Wilson, B. C. In Vivo Fluorescence Spectroscopy and Imaging for Oncological Applications. Photochemistry and Photobiology 68, 603-632 (1998).

91. Tsai, T.-H., Fujimoto, J. \& Mashimo, H. Endoscopic Optical Coherence Tomography for Clinical Gastroenterology. Diagnostics 4, 57-93 (2014).

92. Yang, V. X. D. et al. Endoscopic Doppler optical coherence tomography in the human GI tract: initial experience. Gastrointest. Endosc. 61, 879-890 (2005).

93. Gora, M. J., Suter, M. J., Tearney, G. J. \& Li, X. Endoscopic optical coherence tomography: technologies and clinical applications [Invited]. Biomed. Opt. Express 8, 2405 (2017).

94. Masci, E. et al. Optical coherence tomography in pediatric patients: A feasible technique for diagnosing celiac disease in children with villous atrophy. Dig. Liver Dis. 41, 639-643 (2009).

95. Shen, B. et al. In vivo colonoscopic optical coherence tomography for transmural inflammation in inflammatory bowel disease. Clin. Gastroenterol. Hepatol. 2, 1080-7 (2004).

96. Consolo, P. et al. Optical Coherence Tomography in Inflammatory Bowel Disease: Prospective Evaluation of 35 Patients. Dis. Colon Rectum 51, 1374-1380 (2008).

97. Adler, D. C. et al. Three-dimensional endomicroscopy of the human colon using optical coherence tomography. Opt. Express 17, 784-96 (2009).

98. Gora, M. J. et al. Tethered capsule endomicroscopy enables less invasive imaging of gastrointestinal tract microstructure. Nat. Med. 19, 238-240 (2013).

99. Liang, K. et al. Ultrahigh speed en face OCT capsule for endoscopic imaging. Biomed. Opt. Express 6, 1146 (2015).

100. Spada, C., Hassan, C., Campanale, M. \& Costamagna, G. Colon capsule endoscopy. Tech. Gastrointest. Endosc. 17, 19-23 (2015).

101. Check-Cap. Check-Cap Announces FDA Conditional Approval of IDE to Initiate U.S. Pilot Study of C-Scan. Press Release (2018). Available at: https://www.prnewswire.com/news-releases/check-cap-announces-fdaconditional-approval-of-ide-to-initiate-us-pilot-study-of-c-scan-300764947.html. (Accessed: 11th January 2019)

102. Gluck, N. et al. A novel prepless X-ray imaging capsule for colon cancer screening. Gut 65, 371-373 (2016).

103. Kimchy, Y. et al. Radiographic capsule-based system for non-cathartic colorectal cancer screening. Abdom. Radiol. 42, 1291-1297 (2017).

104. Lifshitz, R. et al. An X-ray-based capsule for colorectal cancer screening incorporating single photon counting technology. in SPIE Physics of Medical Imaging (eds. Flohr, T. G., Lo, J. Y. \& Gilat Schmidt, T.) 10132, 1013210 (2017).

105. US Food and Drug Administration. What are the Radiation Risks from CT ? FDA Website Available at: https://www.fda.gov/Radiation-

EmittingProducts/RadiationEmittingProductsandProcedures/Medicallmaging/MedicalX-Rays/ucm115329.htm. (Accessed: 26th April 2018)

106. van Gelder, R. E. et al. CT Colonography at Different Radiation Dose Levels: Feasibility of Dose Reduction. Radiology 224, 25-33 (2002).

107. Niedermann, R. et al. Prediction of human core body temperature using non-invasive measurement methods. Int. J. Biometeorol. 58, 7-15 (2014).

108. Stewart, I. B., Stewart, K. L., Worringham, C. J. \& Costello, J. T. Physiological Tolerance Times while Wearing Explosive Ordnance Disposal Protective Clothing in Simulated Environmental Extremes. PLoS One 9, e83740 (2014).

109. Halder, S. L. S. et al. Natural History of Functional Gastrointestinal Disorders: A 12-year Longitudinal 
Population-Based Study. Gastroenterology 133, 799-807.e1 (2007).

110. Talley, N. J. Functional gastrointestinal disorders as a public health problem. Neurogastroenterol. Motil. 20, 121-129 (2008).

111. Husebye, E. The patterns of small bowel motility: physiology and implications in organic disease and functional disorders. Neurogastroenterol. Motil. 11, 141-161 (1999).

112. Paine, P., McLaughlin, J. \& Lal, S. Review article: The assessment and management of chronic severe gastrointestinal dysmotility in adults. Alimentary Pharmacology and Therapeutics (2013). doi:10.1111/apt.12496

113. Pandolfino, J. E. \& Kahrilas, P. J. AGA technical review on the clinical use of esophageal manometry. Gastroenterology (2005). doi:10.1053/j.gastro.2004.11.008

114. Arshak, A. et al. Review of the potential of a wireless MEMS and TFT microsystems for the measurement of pressure in the GI tract. Med. Eng. Phys. 27, 347-356 (2005).

115. Stein, E., Berger, Z., Hutfless, S. \& Shah, L. Wireless motility capsule versus other diagnostic technologies for evaluating gastroparesis and constipation: a comparative effectiveness review. Comp. Eff. Rev. (2013).

116. Saad, R. J. \& Hasler, W. L. A technical review and clinical assessment of the wireless motility capsule. Gastroenterology and Hepatology 7, 795-804 (2011).

117. Kloetzer, L. et al. Motility of the antroduodenum in healthy and gastroparetics characterized by wireless motility capsule. Neurogastroenterol. Motil. (2010). doi:10.1111/j.1365-2982.2010.01468.x

118. Hasler, W. L. et al. Heightened colon motor activity measured by a wireless capsule in patients with constipation: relation to colon transit and IBS. Am. J. Physiol. Liver Physiol. 297, G1107-G1114 (2009).

119. Li, P., Kothari, V. \& Terry, B. S. Design and Preliminary Experimental Investigation of a Capsule for Measuring the Small Intestine Contraction Pressure. IEEE Trans. Biomed. Eng. 62, 2702-2708 (2015).

120. Saad, R. J. The Wireless Motility Capsule: a One-Stop Shop for the Evaluation of GI Motility Disorders. Curr. Gastroenterol. Rep. 18, 14 (2016).

121. Tran, K., Brun, R. \& Kuo, B. Evaluation of regional and whole gut motility using the wireless motility capsule: relevance in clinical practice. Therap. Adv. Gastroenterol. 5, 249-260 (2012).

122. Rao, S. S. C., Mysore, K., Attaluri, A. \& Valestin, J. Diagnostic utility of wireless motility capsule in gastrointestinal dysmotility. J. Clin. Gastroenterol. (2011). doi:10.1097/MCG.0b013e3181ff0122

123. Li, P., Kreikemeier-Bower, C., Xie, W., Kothari, V. \& Terry, B. S. Design of a Wireless Medical Capsule for Measuring the Contact Pressure Between a Capsule and the Small Intestine. J. Biomech. Eng. 139, 051003 (2017).

124. Youngin Kim et al. Pressure Monitoring System in Gastro-Intestinal Tract. in Proceedings of the 2005 IEEE International Conference on Robotics and Automation 1321-1326 (IEEE, 2005). doi:10.1109/ROBOT.2005.1570298

125. Cheng, L. K., Du, P. \& O'Grady, G. Mapping and modeling gastrointestinal bioelectricity: from engineering bench to bedside. Physiology (Bethesda). 28, 310-7 (2013).

126. Poscente, M. D. \& Mintchev, M. P. Enhanced electrogastrography: A realistic way to salvage a promise that was never kept? World J. Gastroenterol. 23, 4517-4528 (2017).

127. Woo, S. H. \& Cho, J. H. Telemetry system for slow wave measurement from the small bowel. Med. Biol. Eng. Comput. 48, 277-283 (2010).

128. Woo, S. H., Kim, T. W., Mohy-Ud-Din, Z., Park, I. Y. \& Cho, J. Small intestinal model for electrically propelled capsule endoscopy. Biomed. Eng. Online 10, 108 (2011).

129. Clarysse, S. et al. Postprandial Evolution in Composition and Characteristics of Human Duodenal Fluids in Different Nutritional States. J. Pharm. Sci. 98, 1177-1192 (2009).

130. Bai, J. P. F., Burckart, G. J. \& Mulberg, A. E. Literature Review of Gastrointestinal Physiology in the Elderly, in Pediatric Patients, and in Patients with Gastrointestinal Diseases. J. Pharm. Sci. 105, 476-483 (2016).

131. Fisichella, P. M., Schlottmann, F. \& Patti, M. G. Evaluation of gastroesophageal reflux disease. Updates Surg. 70, 309-313 (2018).

132. Fallingborg, J., Christensen, L. A., Jacobsen, B. A. \& Rasmussen, S. N. Very low intraluminal colonic pH in patients with active ulcerative colitis. Dig. Dis. Sci. 38, 1989-1993 (1993).

133. Nugent, S., Kumar, D., Rampton, D., Yazaki, E. \& Evans, D. Gut pH and transit time in ulcerative colitis appear sufficient for complete dissolution of $\mathrm{pH}$-dependent mesalazine-containing capsules. Gut 46, A781 (2000).

134. Press, A. G. G. et al. Gastrointestinal pH profiles in patients with inflammatory bowel disease. Aliment. Pharmacol. Ther. 12, 673-8 (1998).

135. Fallingborg, J., Pedersen, P. \& Jacobsen, B. A. Small intestinal transit time and intraluminal pH in ileocecal resected patients with Crohn's disease. Dig. Dis. Sci. 43, 702-705 (1998).

136. Colson, R. H. et al. An accurate, long-term, pH-sensitive radio pill for ingestion and implantation. Biotelem. Patient Monit. 8, 213-27 (1981).

137. Hochman, J. A. \& Favaloro-Sabatier, J. Tolerance and Reliability of Wireless pH Monitoring in Children. J. 
Pediatr. Gastroenterol. Nutr. 41, 411-415 (2005).

138. Van Der Schaar, P. J. et al. A novel ingestible electronic drug delivery and monitoring device. Gastrointest. Endosc. 78, 520-528 (2013).

139. Söderlind, E. et al. Validation of the IntelliCap® system as a tool to evaluate extended release profiles in human GI tract using metoprolol as model drug. J. Control. Release 217, 300-307 (2015).

140. Koziolek, M. et al. Investigation of $\mathrm{pH}$ and Temperature Profiles in the GI Tract of Fasted Human Subjects Using the Intellicap® System. J. Pharm. Sci. 104, 2855-2863 (2015).

141. Maurer, J. M. et al. Gastrointestinal pH and Transit Time Profiling in Healthy Volunteers Using the IntelliCap System Confirms Ileo-Colonic Release of ColoPulse Tablets. PLoS One 10, e0129076 (2015).

142. Maqbool, S., Parkman, H. P. \& Friedenberg, F. K. Wireless Capsule Motility: Comparison of the SmartPill@ GI Monitoring System with Scintigraphy for Measuring Whole Gut Transit. Dig. Dis. Sci. 54, 2167-2174 (2009).

143. Rao, S. S. C. et al. Investigation of colonic and whole-gut transit with wireless motility capsule and radiopaque markers in constipation. Clin. Gastroenterol. Hepatol. 7, 537-44 (2009).

144. Hasler, W. L. The use of SmartPill for gastric monitoring. Expert Rev. Gastroenterol. Hepatol. 8, 587-600 (2014).

145. KUO, B. et al. Comparison of gastric emptying of a nondigestible capsule to a radio-labelled meal in healthy and gastroparetic subjects. Aliment. Pharmacol. Ther. 27, 186-196 (2007).

146. Farmer, A. D. Caecal pH is a biomarker of excessive colonic fermentation. World J. Gastroenterol. 20, 5000 (2014).

147. Cummins, G. et al. Luminally expressed gastrointestinal biomarkers. Expert Rev. Gastroenterol. Hepatol. 11, 1119-1134 (2017).

148. Twomey, K. et al. Characterization of the Electrochemical Behavior of Gastrointestinal Fluids Using a Multielectrode Sensor Probe. IEEE Trans. Biomed. Eng. 58, 2521-2527 (2011).

149. Caffrey, C. M., Twomey, K. \& Ogurtsov, V. I. Development of a wireless swallowable capsule with potentiostatic electrochemical sensor for gastrointestinal track investigation. Sensors Actuators B Chem. 218, 8-15 (2015).

150. Yen, Y.-K., Capua, E. \& Naaman, R. Application of a GaAs-Based Sensor for Detecting Hemoglobin in Gastrointestinal Environments. IEEE Sens. J. 17, 660-666 (2017).

151. Schostek, S. et al. Telemetric real-time sensor for the detection of acute upper gastrointestinal bleeding. Biosens. Bioelectron. 78, 524-529 (2016).

152. Qiao, P., Liu, H., Yan, X., Jia, Z. \& Pi, X. A Smart Capsule System for Automated Detection of Intestinal Bleeding Using HSL Color Recognition. PLoS One 11, e0166488 (2016).

153. Kapsoritakis, A. N. et al. Mean platelet volume: A useful marker of inflammatory bowel disease activity. Am. J. Gastroenterol. (2001). doi:10.1016/S0002-9270(00)02414-X

154. Schostek, S. et al. Volunteer Case Series of a New Telemetric Sensor for Blood Detection in the Upper Gastrointestinal Tract: The HemoPill. Dig. Dis. Sci. 61, 2956-2962 (2016).

155. Mimee, M. et al. An ingestible bacterial-electronic system to monitor gastrointestinal health. Science (80-. ). 360, 915-918 (2018).

156. Momozawa, Y., Deffontaine, V., Louis, E. \& Medrano, J. F. Characterization of bacteria in biopsies of colon and stools by high throughput sequencing of the V2 region of bacterial 16s rRNA gene in human. PLoS One 6, (2011).

157. Wolin, M. J. Fermentation in the rumen and human large intestine. Science (80-. ). 213, 1463-1468 (1981).

158. Kalantar-Zadeh, K. et al. A human pilot trial of ingestible electronic capsules capable of sensing different gases in the gut. Nat. Electron. 1, 79-87 (2018).

159. Kalantar-zadeh, K. et al. Intestinal Gas Capsules: A Proof-of-Concept Demonstration. Gastroenterology 150, 37-39 (2016).

160. Ou, J. Z. et al. Potential of in vivo real-time gastric gas profiling: A pilot evaluation of heat-stress and modulating dietary cinnamon effect in an animal model. Sci. Rep. 6, 1-9 (2016).

161. Deutsch, J. C. The optical biopsy of small gastric lesions. Gastrointest. Endosc. 79, 64-65 (2014).

162. Qumseya, B. J. et al. Advanced Imaging Technologies Increase Detection of Dysplasia and Neoplasia in Patients With Barrett's Esophagus: A Meta-analysis and Systematic Review. Clin. Gastroenterol. Hepatol. 11, 1562-1570.e2 (2013).

163. Su, P. et al. Efficacy of confocal laser endomicroscopy for discriminating colorectal neoplasms from nonneoplasms: a systematic review and meta-analysis. Color. Dis. 15, e1-e12 (2013).

164. Ypsilantis, E., Pissas, D., Papagrigoriadis, S. \& Haji, A. Use of Confocal Laser Endomicroscopy to Assess the Adequacy of Endoscopic Treatment of Gastrointestinal Neoplasia. Surg. Laparosc. Endosc. Percutan. Tech. 25, 1-5 (2015).

165. Fugazza, A. et al. Confocal Laser Endomicroscopy in Gastrointestinal and Pancreatobiliary Diseases: A Systematic Review and Meta-Analysis. Biomed Res. Int. 2016, 1-31 (2016).

166. Mori, Y., Kudo, S., Berzin, T., Misawa, M. \& Takeda, K. Computer-aided diagnosis for colonoscopy. 
Endoscopy 49, 813-819 (2017).

167. Leggett, C. L. \& Wang, K. K. Computer-aided diagnosis in GI endoscopy: looking into the future. Gastrointest. Endosc. 84, 842-844 (2016).

168. Kang, J. U. Virtual biopsy. Proc. IEEE 98, 503-505 (2010).

169. Neumann, H. et al. Review article: In vivo imaging by endocytoscopy. Aliment. Pharmacol. Ther. 33, 11831193 (2011).

170. Tabatabaei, N. et al. Clinical Translation of Tethered Confocal Microscopy Capsule for Unsedated Diagnosis of Eosinophilic Esophagitis. Sci. Rep. 8, 2631 (2018).

171. Zagaynova, E., Gladkova, N., Shakhova, N., Gelikonov, G. \& Gelikonov, V. Endoscopic OCT with forwardlooking probe: Clinical studies in urology and gastroenterology. J. Biophotonics 1, 114-128 (2008).

172. Hatta, W. et al. Optical coherence tomography for the staging of tumor infiltration in superficial esophageal squamous cell carcinoma. Gastrointest. Endosc. 71, 899-906 (2010).

173. Isenberg, G. et al. Accuracy of endoscopic optical coherence tomography in the detection of dysplasia in Barrett's esophagus: a prospective, double-blinded study. Gastrointest. Endosc. 62, 825-831 (2005).

174. Chauhan, S. S. et al. Confocal laser endomicroscopy. Gastrointest. Endosc. 80, 928-938 (2014).

175. Carignan, C. S. \& Yagi, Y. Optical endomicroscopy and the road to real-time, in vivo pathology: present and future. Diagn. Pathol. 7, 98 (2012).

176. Adrain, A. L. et al. High-resolution endoluminal sonography is a sensitive modality for the identification of Barrett's metaplasia. Gastrointest. Endosc. 46, 147-151 (1997).

177. Murata, Y. et al. Small ultrasonic probes for determination of the depth of superficial esophageal cancer. Gastrointest. Endosc. 44, 23-28 (1996).

178. Nguyen, N. Q. \& Leong, R. W. L. Current application of confocal endomicroscopy in gastrointestinal disorders. J. Gastroenterol. Hepatol. 23, 1483-1491 (2008).

179. Thompson, A. J. et al. The potential role of optical biopsy in the study and diagnosis of environmental enteric dysfunction. Nature Reviews Gastroenterology and Hepatology (2017). doi:10.1038/nrgastro.2017.147

180. Roy, H. K., Goldberg, M. J., Bajaj, S. \& Backman, V. Colonoscopy and optical biopsy: Bridging technological advances to clinical practice. Gastroenterology 140, 1863-1867 (2011).

181. Than, T. D., Alici, G., Zhou, H. \& Li, W. A review of localization systems for robotic endoscopic capsules. IEEE Trans. Biomed. Eng. 59, 2387-2399 (2012).

182. Mateen, H., Basar, R., Ahmed, A. U. \& Ahmad, M. Y. Localization of Wireless Capsule Endoscope: A Systematic Review. IEEE Sens. J. 17, 1197-1206 (2017).

183. Ahmad, O. F. et al. Artificial intelligence and computer-aided diagnosis in colonoscopy: current evidence and future directions. Lancet Gastroenterol. Hepatol. 4, 71-80 (2019).

184. Brandao, P. et al. Towards a Computed-Aided Diagnosis System in Colonoscopy: Automatic Polyp Segmentation Using Convolution Neural Networks. J. Med. Robot. Res. 03, 1840002 (2018).

185. Koulaouzidis, A. et al. Novel experimental and software methods for image reconstruction and localization in capsule endoscopy. Endosc. Int. Open 06, E205-E210 (2018).

186. Visentini-Scarzanella, M. et al. A structured light laser probe for gastrointestinal polyp size measurement: a preliminary comparative study. Endosc. Int. Open (2018). doi:10.1055/a-0577-2798

187. Dimas, G., lakovidis, D. K., Karargyris, A., Ciuti, G. \& Koulaouzidis, A. An artificial neural network architecture for non-parametric visual odometry in wireless capsule endoscopy. Meas. Sci. Technol. 28, 094005 (2017).

188. Fischer, D., Schreiber, R., Levi, D. \& Eliakim, R. Capsule endoscopy: the localization system. Gastrointest. Endosc. Clin. N. Am. 14, 25-31 (2004).

189. Ciuti, G., Menciassi, A. \& Dario, P. Capsule Endoscopy: From Current Achievements to Open Challenges. IEEE Rev. Biomed. Eng. 4, 59-72 (2011).

190. Hu, C. et al. A Cubic 3-Axis Magnetic Sensor Array for Wirelessly Tracking Magnet Position and Orientation. IEEE Sens. J. 10, 903-913 (2010).

191. Taddese, A. Z. et al. Enhanced Real-Time Pose Estimation for Closed Loop Robotic Manipulation of Magnetically Actuated Capsule Endoscopes. Int. J. Rob. Res. (2018).

192. Levinthal, G. N., Burke, C. A. \& Santisi, J. M. The accuracy of an endoscopy nurse in interpreting capsule endoscopy. Am. J. Gastroenterol. 98, 2669-2671 (2003).

193. Lai, L. H. et al. Inter-observer variations on interpretation of capsule endoscopies. Eur. J. Gastroenterol. Hepatol. 18, 283-286 (2006).

194. Riphaus, A., Richter, S., Vonderach, M. \& Wehrmann, T. Capsule endoscopy interpretation by an endoscopy nurse - a comparative trial. Z Gastroenterol 47, 273-6 (2009).

195. Dokoutsidou, H. et al. A study comparing an endoscopy nurse and an endoscopy physician in capsule endoscopy interpretation. Eur. J. Gastroenterol. Hepatol. 23, 166-170 (2011).

196. Deeba, F., Islam, M., Bui, F. M. \& Wahid, K. A. Performance assessment of a bleeding detection algorithm for endoscopic video based on classifier fusion method and exhaustive feature selection. Biomed. Signal Process. Control 40, 415-424 (2018). 
197. Hassan, A. R. \& Haque, M. A. Computer-aided gastrointestinal hemorrhage detection in wireless capsule endoscopy videos. Comput. Methods Programs Biomed. 122, 341-353 (2015).

198. Sainju, S., Bui, F. M. \& Wahid, K. A. Automated bleeding detection in capsule endoscopy videos using statistical features and region growing. J. Med. Syst. 38, (2014).

199. Buscaglia, J. M. et al. Performance Characteristics of the Suspected Blood Indicator Feature in Capsule Endoscopy According to Indication for Study. Clin. Gastroenterol. Hepatol. 6, 298-301 (2008).

200. Doi, K. Computer-aided diagnosis in medical imaging: Historical review, current status and future potential. Comput Med Imaging Graph 31, 198-211 (2007).

201. Liu, D. Y. et al. Identification of lesion images from gastrointestinal endoscope based on feature extraction of combinational methods with and without learning process. Med. Image Anal. 32, 281-294 (2016).

202. lakovidis, D. K. \& Koulaouzidis, A. Automatic lesion detection in wireless capsule endoscopy - A simple solution for a complex problem. Image Process. (ICIP), 2014 IEEE Int. Conf. on. IEEE 2236-2240 (2014). doi:10.1109/ICIP.2014.7025453

203. Gan, T., Wu, J. C., Rao, N. N., Chen, T. \& Liu, B. A feasibility trial of computer-aided diagnosis for enteric lesions in capsule endoscopy. World J. Gastroenterol. 14, 6929-6935 (2008).

204. Li, B. et al. Using ensemble classifier for small bowel ulcer detection in wireless capsule endoscopy images. IEEE Int. Conf. Robot. Biomimetics 2326-2331 (2009). doi:10.1109/ROBIO.2009.5420455

205. Eid, A., Charisis, V. S., Hadjileontiadis, L. J. \& Sergiadis, G. D. A curvelet-based lacunarity approach for ulcer detection from Wireless Capsule Endoscopy images. Proc. CBMS 2013 - 26th IEEE Int. Symp. Comput. Med. Syst. 273-278 (2013). doi:10.1109/CBMS.2013.6627801

206. Koshy, N. E. \& Gopi, V. P. A new method for ulcer detection in endoscopic images. in 2nd International Conference on Electronics and Communication Systems, ICECS 2015 1725-1729 (2015). doi:10.1109/ECS.2015.7124881

207. Li, B. \& Meng, M. Q. H. Tumor recognition in wireless capsule endoscopy images using textural features and SVM-based feature selection. IEEE Trans. Inf. Technol. Biomed. 16, 323-329 (2012).

208. Liu, G., Yan, G., Kuang, S. \& Wang, Y. Detection of small bowel tumor based on multi-scale curvelet analysis and fractal technology in capsule endoscopy. Comput. Biol. Med. 70, 131-138 (2016).

209. Barbosa, D. C., Roupar, D. B., Ramos, J. C., Tavares, A. C. \& Lima, C. S. Automatic small bowel tumor diagnosis by using multi-scale wavelet-based analysis in wireless capsule endoscopy images. Biomed. Eng. Online 11, 3 (2012).

210. Barbosa, D. J. C., Ramos, J., Correia, J. H. \& Lima, C. S. Automatic detection of small bowel tumors in capsule endoscopy based on color curvelet covariance statistical texture descriptors. Proc. 31st Annu. Int. Conf. IEEE Eng. Med. Biol. Soc. Eng. Futur. Biomed. EMBC 2009 6683-6686 (2009). doi:10.1109/IEMBS.2009.5334013

211. Li, B., Meng, M. Q. H. \& Lau, J. Y. W. Computer-aided small bowel tumor detection for capsule endoscopy. Artif. Intell. Med. 52, 11-16 (2011).

212. Mamonov, A. V, Figueiredo, I. N., Figueiredo, P. N. \& Tsai, Y. R. Automated polyp detection in colon capsule endoscopy by Automated polyp detection in colon capsule endoscopy. Ices Rep. 13-10 33, 1-16 (2013).

213. Fu, Y., Zhang, W., Mandal, M. \& Meng, M. Q. H. Computer-aided bleeding detection in WCE video. IEEE J. Biomed. Heal. Informatics 18, 636-642 (2014).

214. Yeh, J.-Y., Wu, T.-H. \& Tsai, W.-J. Bleeding and Ulcer Detection Using Wireless Capsule Endoscopy Images. J. Softw. Eng. Appl. 07, 422-432 (2014).

215. Xiaoying Liu, lia Gu, Yaoqin Xie, lun X. and W. Q. A New Approach to Detecting Ulcer and Bleeding in Wireless Capsule Endoscopy Images. IEEE-EMBS Int. Conf. Biomed. Heal. Informatics 25, 737-740 (2012).

216. Yuan, Y., Li, B. \& Meng, M. Q. H. Bleeding Frame and Region Detection in the Wireless Capsule Endoscopy Video. IEEE J. Biomed. Heal. Informatics 20, 624-630 (2016).

217. Liedlgruber, M. \& Uhl, A. Computer-aided decision support systems for endoscopy in the gastrointestinal tract: A review. IEEE Rev. Biomed. Eng. 4, 73-88 (2011).

218. Karargyris, A. \& Bourbakis, N. Detection of small bowel polyps and ulcers in wireless capsule endoscopy videos. IEEE Trans. Biomed. Eng. 58, 2777-2786 (2011).

219. Szczypiński, P., Klepaczko, A., Pazurek, M. \& Daniel, P. Texture and color based image segmentation and pathology detection in capsule endoscopy videos. Comput. Methods Programs Biomed. 113, 396-411 (2014).

220. Garcia-Allende, P. B. et al. Morphological analysis of optical coherence tomography images for automated classification of gastrointestinal tissues. Biomed. Opt. Express 2, 2821 (2011).

221. Ughi, G. J. et al. Automated segmentation and characterization of esophageal wall in vivo by tethered capsule optical coherence tomography endomicroscopy. Biomed. Opt. Express 7, 409 (2016).

222. Tsai, T.-H., Leggett, C. L. \& Trindade, A. J. Optical coherence tomography in gastroenterology: a review and future outlook. J. Biomed. Opt. 22, 1 (2017).

223. Inomata, H. et al. Efficacy of a novel auto-fluorescence imaging system with computer-assisted color analysis for assessment of colorectal lesions. World J. Gastroenterol. 19, 7146-7153 (2013). 
224. Kanesaka, T. et al. Computer-aided diagnosis for identifying and delineating early gastric cancers in magnifying narrow-band imaging. Gastrointest. Endosc. 87, 1339-1344 (2018).

225. Gadermayr, M. NARROW BAND IMAGING VERSUS WHITE-LIGHT : WHAT IS BEST FOR COMPUTERASSISTED DIAGNOSIS OF CELIAC DISEASE ? Institute of Imaging and Computer Vision, RWTH Aachen , Germany Department of Computer Sciences , University of Salzburg , Austria St . Anna Childre. 355-359 (2016).

226. Takemura, Y. et al. Computer-aided system for predicting the histology of colorectal tumors by using narrowband imaging magnifying colonoscopy (with video). Gastrointest. Endosc. 75, 179-185 (2012).

227. Tamaki, T. et al. Computer-aided colorectal tumor classification in NBI endoscopy: Using local features. Med. Image Anal. 17, 78-100 (2013).

228. Medtronic. SmartPill - Product Information. Medtronic - SmartPill WebPage Available at: http://www.medtronic.com/covidien/en-us/products/motility-testing/smartpill-motility-testing-system.html. (Accessed: 27th February 2018)

229. Medtronic. BRAVO - Product Brochure. Medtronic - BRAVO Webpage Available at: http://www.medtronic.com/content/dam/covidien/library/us/en/product/diagnostic-testing/bravo-reflux-testingsystem-product-brochure.pdf. (Accessed: 27th February 1980)

230. FDA Approval of Capsocam Plus. FDA Website (2016). Available at: https://www.accessdata.fda.gov/cdrh_docs/pdf16/K161773.pdf. (Accessed: 9th January 2019)

231. Medtronic. Pillcam UGI - Capsule Specifications. Medtronic - Pillcam UGI Webpage Available at: http://www.medtronic.com/covidien/en-us/products/capsule-endoscopy/pillcam-ugi-system.html. (Accessed: 27th February 2018)

232. Medtronic. Pillcam SB-3 - Capsule Specifications. Medtronic - Pillcam SB-3 Webpage Available at: http://www.medtronic.com/covidien/en-us/products/capsule-endoscopy/pillcam-sb-3-system.html. (Accessed: 27th February 2018)

233. Olympus. EC-S10 - Capsule Specifications. Olympus Webpage Available at: http://medical.olympusamerica.com/products/endocapsule-maj-2027. (Accessed: 27th February 2018)

234. Capsovision. Capsocam Plus - Capsule Specifications. Capsovision Webpage Available at: http://www.capsovision.com/physicians/product-specifications. (Accessed: 27th February 2018)

235. Aquilant Endoscopy. OMOM 2 - Capsule Specifications. Aqualiant Endoscopy Webpage Available at: http://www.aquilantendoscopy.com/products/products_detail.asp?subp=products_by_all.asp\&idProduct=1287 4. (Accessed: 27th February 2018)

236. Zhang, L. et al. Diagnostic value of OMOM capsule endoscopy for small bowel diseases in adults. Exp. Ther. Med. (2018). doi:10.3892/etm.2018.5864

237. Pioche, M. et al. Prospective randomized comparison between axial- and lateral-viewing capsule endoscopy systems in patients with obscure digestive bleeding. Endoscopy 46, 479-484 (2014).

238. Tontini, G. E. et al. Extensive small-bowel Crohn's disease detected by the newly introduced $360^{\circ}$ panoramic viewing capsule endoscopy system. Endoscopy 46, (2014).

239. Motilis. Motilis - Motility Capsule Specifications. Motilis Webpage Available at: http://www.motilis.com/V3/index.php?nav=4. (Accessed: 27th February 2018)

240. Worsøe, J. et al. Gastric transit and small intestinal transit time and motility assessed by a magnet tracking system. BMC Gastroenterol. 11, 145 (2011).

241. Becker, D. et al. Novel Orally Swallowable IntelliCap® Device to Quantify Regional Drug Absorption in Human GI Tract Using Diltiazem as Model Drug. AAPS PharmSciTech 15, 1490-1497 (2014).

242. Spada, C. et al. Colon capsule endoscopy: European Society of Gastrointestinal Endoscopy (ESGE) Guideline. Endoscopy 44, 527-536 (2012).

243. Atkins, D. et al. Grading quality of evidence and strength of recommendations. BMJ 328, 1490 (2004).

244. Harbour, R. \& Miller, J. A new system for grading recommendations in evidence based guidelines. BMJ 323, 334-6 (2001).

245. SynMed. Mirocam - Capsule Specifications. SynMed Webpage Available at: http://www.synmed.co.uk/products_capsule_endoscopy.htm. (Accessed: 27th February 2018)

246. Intromedic. Mirocam - Capsule Specifications. Intromedic Webpage Available at: http://www.intromedic.com/eng/item/item_010100_view.asp?search_kind=\&gotopage=1\&no=3. (Accessed: 27th February 2018) 